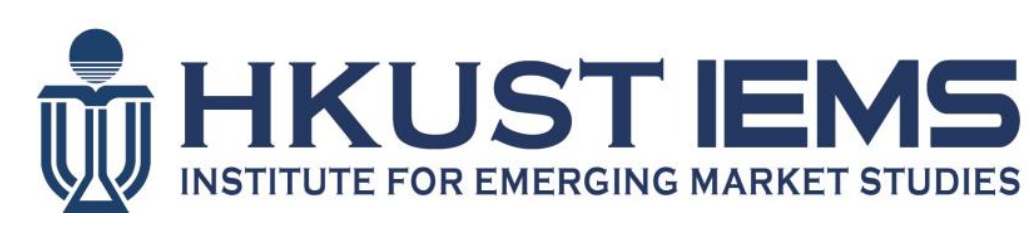

\title{
Spillovers in Asset Prices: The Curious Case of Haunted Houses
}

\author{
Utpal Bhattacharya, Daisy Huang, \\ Kasper Meisner Nielsen
}

HKUST IEMS Working Paper No. 2019-63

May 2019

\footnotetext{
HKUST IEMS working papers are distributed for discussion and comment purposes. The views expressed in these papers are those of the authors and do not necessarily represent the views of HKUST IEMS.

More HKUST IEMS working papers are available at: http://iems.ust.hk/WP
} 


\title{
Spillovers in Asset Prices: The Curious Case of Haunted Houses
}

\author{
Utpal BHATTACHARYA, Daisy HUANG, Kasper Meisner NIELSEN \\ HKUST IEMS Working Paper No. 2019-63 \\ May 2019
}

\begin{abstract}
Exploiting the unique institutional setting of Hong Kong's real estate market, we uncover a curious ripple effect of haunted houses on the prices of nearby houses. Prices drop on average $20 \%$ for units that become haunted, $5 \%$ for units on the same floor, $3 \%$ for units in the same block, and 1\% for units in the same estate. Our study makes two contributions. First, our results provide an estimate of a large negative spillover on asset prices caused by an idiosyncratic shock to the perceived quality of an asset. Second, since we observe that this ripple effect exists even if the haunted house is not sold, we can isolate the quality channel from the price pressure channel. We find that the quality channel contributes significantly to spillovers in asset prices.
\end{abstract}

Keywords: fire sales, negative spillovers, haunted houses

JEL: $\quad$ D62, H23, R21, R31

\section{Author's contact information}

\section{Utpal Bhattacharya}

Institute for Emerging Market Studies

Hong Kong University of Science and Technology

E: ubhattac@ust.hk

\section{Daisy Huang}

Nanjing Audit University

E:daisy.vspe@gmail.com

\section{Kasper Meisner Nielsen}

Institute for Emerging Market Studies

Hong Kong University of Science and Technology

E:nielsen@ust.hk 


\section{Introduction}

Spillovers - the notion that the consequences of an economic activity can affect third partiesin asset prices have gained attention following the global financial crisis. The interest among academics, market participants and policy makers has intensified because liquidation of assets can lead to downward spirals or cascades in asset prices and net worth of market participants (Kiyotaki and Moore, 1997; Gromb and Vayanos, 2002; Coval and Stafford, 2007; Campbell, Giglio, and Pathak, 2011) and creditors (Acharya, Bharath, and Srinivasan, 2007), resulting in real effects through reduced investment and output (Kiyotaki and Moore, 1997; Ivashina and Scharfstein, 2010; and Shleifer and Vishny, 2011).

Prior literature on spillovers in asset prices has mainly been preoccupied with identifying the effect of fire sales on asset prices (see survey by Shleifer and Vishny, 2011) using transaction based dataset on airplanes (Pulvino, 1998), corporate bankruptcies (Eckbo and Thorburn, 2008; Bernstein et al, 2017), foreclosures (Campbell, Giglio, and Pathak, 2011), and mutual funds (Coval and Stafford, 2007). Collectively, these studies have established that fire sales lead to substantial reductions in asset prices, and result in negative spillover effects on prices of similar assets. Spillovers in asset prices, however, might occur not just due to the price pressure from a fire sale, but also, as we argue in this study, because of a change in the perceived quality of the asset.

To convincingly document that spillover effects in asset prices can be driven by a change in the perceived quality of the asset, we identify an idiosyncratic negative shock - a unit being declared as "haunted" due to a murder, suicide or other unnatural death. We analyze the spillover effect on prices of neighboring houses, and examine whether it is driven by the price pressure channel (prices of nearby houses are depressed because of the fire sale of the haunted unit), the change in perceived quality channel (prices of nearby houses are depressed even if the haunted unit is not sold), or both. Separating these two channels is possible in our setting, because we can observe nearby house prices, irrespective of whether 
the affected unit is sold or not, allowing us to identify spillover effects driven by a change in the perceived quality of the asset.

We analyze Hong Kong's residential real estate market because it offers four institutional features that help our identification strategy. First, since a population of 7.31 million (2015) lives in a small area that is less than $25 \%$ of its 1,106 square kilometers (most of the other area is reserved for country parks and nature reserves), residential real estate mainly consists of units in high rise apartment blocks sharing common facilities on a small plot of land, called an estate. Although estates are heterogeneous, blocks within an estate and the units within a block are fairly homogenous. ${ }^{1}$ This helps in our identification because it makes spillovers in prices easier to identify, and allow us to control for unobserved heterogeneity in the cross-section of apartments as well as in the time-series.

Second, residents are very wary of haunted houses, and sellers have to disclose whether a house is haunted. ${ }^{2}$ As a result, real estate companies maintain databases of haunted houses complied from local press reports covering these tragic events. ${ }^{3}$ The focus on haunted houses helps our identification, because unnatural death is an idiosyncratic negative shock to the perceived quality of the unit. Third, as the Hong Kong real estate market is very liquid and the flow of haunted houses is large in number (in our sample of liquid estates, from 2000 to 2015, 898 units were declared as haunted), we have a sample size with sufficient statistical power to detect spillovers in a small geographic area with homogenous

\footnotetext{
${ }^{1}$ In our sample, each estate has an average of 12 blocks, each block has an average of 26 floors, and each floor has an average of 5 units. Thus, the average estate in our sample consists of 1,560 apartments in a small area.

2 In Jopard Holdings Limited v. Ladefaith Limited and Centaline Property Agency Limited (HCA3775/2001), the Property Agent lost the case because "the Agent did not exercise reasonable care and skill in the collection and passing on of information concerning the Property." The information that was not revealed was the tragic death of a 4-year-old boy who had fallen from the balcony of the unit a year before the sale.

(http://legalref.judiciary.gov.hk/lrs/common/search/search result detail frame.jsp?DIS=43673\&QS=\%2B\&TP=JU)
}

3 See, for example, http://www.squarefoot.com.hk/haunted/ 
quality of units. ${ }^{4}$ Fourth, and finally, the institutional setting makes it unlikely that local market conditions differentially affect haunted and non-haunted units, floors or blocks within an estate, because of the close proximity. ${ }^{5}$ This bolsters our identification strategy and makes it reasonable to attribute the effect of haunted houses on nearby apartments to the spillover effect.

To examine the effect of haunted houses on prices we follow a standard approach in real estate economics and regress the logarithm of the price on apartment characteristics, apartment fixed-effects, and year-calendar month fixed effects. We find that affected units sell at an average discount of $20 \%$ after they become haunted. Apartments on the affected floor (excluding the affected unit) sell for an average discount of $5 \%$, while apartments in the same block (excluding the affected floor) sell at an average discount of 3\%. Finally, apartments in the same estate (excluding the affected block) sell at a modest discount of $1 \%$. The documented ripple effects of haunted houses suggest that the tragic event induces a negative spillover effect on the prices of nearby apartments. Amongst the tragic events that we consider, murder has the most dramatic ripple effect.

Interestingly, price recovery is slow. We find in our panel that prices of the haunted units do not seem to recover at all during our 16-year sample period. The prices of its affected neighbors in the same floor, block or apartment, do recover, albeit very slowly.

Our main result is that a large fraction of the spillover effect in prices is driven by a perceived quality channel. We document this by comparing the spillover effect when the affected unit is sold (driven

\footnotetext{
${ }_{4}$ Andersen and Nielsen (2017), who use sudden deaths as the exogenous event to document drops in houses that have fire sales, cannot analyze spillovers because of a small sample size.

5 Haunted houses provides an ideal solution to the identification problem To quote Campbell, Giglio and Pathak (2011): "Ideally, we would like an instrument that influences foreclosures but that does not influence house prices except through foreclosures: however, we have not been able to find such an instrument."
} 
by price pressure and change in perceived quality), to spillover effects when the affected unit is not sold (only driven by the change in the perceived quality). On the affected floor, most of the 5 percentage point decline in prices is caused by the change in the perceived quality channel. For apartments in the affected block or estate, the quality channel accounts for about half of the discount, while the price pressure channel accounts for the other half. To this end, our study is the first to identify a spillover effect, through the perceived quality channel, over and above the price pressure channel.

How relevant are our research findings for other parts of the world? We address this question in three ways. First, we search Factiva for newspaper articles from Australia, United Kingdom and United States using keywords related to unnatural deaths (murder, homicide, suicide, etc.) and real estate transactions (property, house, transaction, etc.). To ensure that we get an unbiased sample of newspaper articles, our search terms do not include keywords related to discount or price drops. Following this procedure, we identify 101 newspaper articles featuring stories about the effect of unnatural death on house prices. For example, New York Times (Nov 24, 2016) interviewed Randall Bell, an economist who has consulted on the appraisals of notorious properties, like the homes of O. J. Simpson and Jon Benet Ramsey. According to Bell, the stigma can result in 25 percent lower prices. If we take an average of the quoted price effects in the 101 articles, we find that the value of affected units drop by 24 percent. The quoted discount is remarkably stable across countries. We find a 25 percent decline in Australia (18 articles), 25 percent in United Kingdom (20 articles), and 25 percent in United States (63 articles). In comparison, we find that affected units in Hong Kong decline by 20 percent following an unnatural death. 
Second, we find that in the U.S. legal system, as in Hong Kong, it is illegal for a seller to hide the fact that the property being sold has a reputation of being haunted. ${ }^{6}$ Third, we find that web-based services like the website, www.diedinhouse.com, helps potential buyers in the U.S. to find out if anyone has died at a given address. This suggests that potential buyers find this information to be useful. Based on these three observations, we conclude that house price discounts due to unnatural deaths are relevant outside of Hong Kong.

Section II presents our data, and explains the institutional setting surrounding residential real estate and haunted houses in Hong Kong. Section III presents the results, while Section IV considers whether discounts are driven by the price pressure channel, the quality channel, or both. Section V considers the external validity of our results, and Section VI concludes.

\section{Data}

\section{II.A. Estates in Hong Kong}

The residential real estate market in Hong Kong consists of a private and a public sector. This study focuses on the private sector, which represents around $50 \%$ of the market share. We exclude the public sector, because property values are distorted by large government subsidies and sales restrictions.

The institutional setting of Hong Kong's private market for residential real estate is helpful for our identification strategy. Due to Hong Kong's rugged topography with steep hills, buildable land is scarce. The scarcity of buildable land combined with population growth has led to pervasive construction of high-rise apartment blocks, resulting in one of the highest population densities in the world. In the

\footnotetext{
${ }^{6}$ In the case Stambovsky v. Ackley, the Supreme Court of New York, Appellate Division, ruled in 1991 that a seller must disclose that a house has a reputation for being haunted when there is a fiduciary relationship or in cases of fraud or misrepresentation, because such a reputation impairs the value of the house.

(https://en.wikipedia.org/wiki/Stambovsky_v._Ackley)
} 
most densely populated district, Kwun Tong, around 57,000 people live per square kilometer of land. In comparison, the most densely populated municipality in the U.S., Guttenberg (NJ) has 22,000 people per square kilometer. Economies of scale, combined with Hong Kong Government's monopoly on land, have led to large scale real estate developments that are referred to as estates. The typical estate consists of several identical blocks sharing amenities such as carparks, fitness center, shuttle buses, and swimming pool. Each block typically consists of 20 to 80 floors sharing a lobby area, while each floor is subdivided into four to eight units with shared access by elevators and stair cases. This helps in our identification because it alleviates the concern that local market conditions differentially affect haunted and nonhaunted units or floors or blocks within an estate, because apartments within a block are homogeneous and blocks are very close to each other and share the same amenities. These institutional features make it easier to convincingly identify spillovers in prices.

To understand the nature of an estate it is helpful to zoom into one: Dawning Views. We start with a helicopter view of Hong Kong. Hong Kong consists of three territories: Hong Kong Island, Kowloon and New Territories. These territories are further divided into districts. Hong Kong Island has four districts, Kowloon has five districts, and New Territories has nine districts. Appendix A1 maps the 18 districts. Appendix A2 zooms in on one estate, Dawning Views, in the North District of the New Territories. Appendix A3 shows a picture of the blocks of Dawning Views. Appendix A4 gives the estate layout of Dawning Views, while Appendix A5 shows the floor plan of floors 8 to 17 in Block 12 of Dawning Views, which have 8 units per floor. Collectively, Appendix A2 to A5 visualize the advantage of using Hong Kong's residential real estate market to identify spillovers in asset prices and uncover whether spillovers are driven by the price pressure channel, the quality channel, or both. Apartments within a block are fairly homogenous, and blocks within an estate share amenities as well as the same geographic location. 
Our data cover all private residential real estate transactions in Hong Kong between 2000 and 2015. There were 1,124,348 of them. The data are maintained by EPRC Ltd., a commercial real estate agency in Hong Kong, and the data are available for sale to the public. The data include the estate name and location, the address of the block, floor, and unit, some property characteristics, transaction date, and price.

The average unit in Hong Kong costs 4.21 million HKD (541,000 USD), and has an interior size of 594.3 square foot (55.2 square meter), making Hong Kong one of the most expensive cities in the world with an average price of 7,094 HKD (912 USD) per square foot, equivalent to 76,400 HKD (9,800 USD) per square meter. Most transactions occur in the New Territories, followed by Kowloon and Hong Kong Island. There is a lot of heterogeneity in these real estate transactions. The median growth in unit prices is $8.8 \%$ per year in the period 2000 to 2015 , the $25^{\text {th }}$ percentile being $5.4 \%$ and the $75^{\text {th }}$ percentile being $12.6 \% .^{7}$

Although there are 7,352 estates in Hong Kong, we focus in the current version of this study on the most liquid estates. A liquid estate is defined as estates with 1,000 or more transactions over our sample period, equivalent to around 5 transactions per month. Following this definition, 214 estates are classified as liquid (2.9\% of all estates). Although this is a small fraction of all estates in our sample, more than half of the transactions $(57.5 \%)$ in our data are located in a liquid estate. The concentration of transactions in liquid estates is illustrated in Figure 1, which plots, in blue, the cumulative number of transactions per year sorted by the liquidity of the estate measured by the illiquidity rank (the most liquid estate takes the value 0 , while the least liquid estate takes the value one). The red line is the cut-off

\footnotetext{
7 We analyze units with at least two transactions in our sample period. The growth rate in unit price per year is calculated from the price of the first transaction to the price of the last transaction.
} 
between liquid and illiquid estates and, as can be observed in this figure, more than half of the transactions $(57.5 \%)$ in our data are located in a liquid estate.

Figure 2 shows that the market share of liquid estates has been almost constant over the sample period both in terms of number of transactions and value of transactions. Finally, Figure 3 shows that the price per square feet in liquid and illiquid estates have followed a parallel trend, with the exception of 2011 and 2012 where prices of illiquid estates appreciated more than for liquid estates. We note that this difference is driven by location as properties on Hong Kong Island appreciated faster than units in Kowloon and New Territories during these years. We conclude from these three figures that our sample of transactions in liquid estates is fairly representative for the residential real estate market in Hong Kong.

While we focus on the most liquid estates, there is substantial heterogeneity even in this subset. The largest estate in our sample of liquid estates, Mei Foo Sun Chuen, consists of 99 high-rise blocks with a total number of 13,500 units. During our sample period, 13,867 units in Mei Foo Sun Chuen are sold for a total transaction value of 45.2 billion HKD (5.8 billion USD). The smallest estate in our sample of liquid estates, LaGrove, consists of only 542 units. During our sample period, 1,000 units in LaGrove are sold for a total transaction value of 2.7 billion HKD (350 million USD).

Table 1 reports detailed descriptive statistics showing the difference between liquid and illiquid estates. Panel A of Table 1 shows that units in liquid estates are slightly smaller (589 vs. 603 square feet), younger (10.4 vs. 21.6 years), sell at lower prices (3.88 vs. 4.67 million HKD) and are cheaper (6,094 vs 6,917 HKD per square feet) compared to illiquid estates. These differences are statistically significant. Part of the difference in price can be attributed to location as most (least) liquid estates are in New Territories (Hong Kong Island)_-see Panel B of Table 1-and property prices in the New Territories compared to property prices in Hong Kong Island, due to the longer distance to the central business 
district around Victoria Harbor, are lower. The number of transactions across year, as seen in Panel C of Table 1, have an inverse U pattern in the period 2000 to 2015 for both liquid and illiquid estates. Panel D of Table 1 shows no seasonal pattern for both liquid and illiquid estates.

\section{II.B. Haunted Houses}

A haunted house is a house where an unnatural death occurred. Unnatural deaths include accidents, murder, and suicide. To cater to home buyers' wariness of haunted houses, property information websites and real estate agents in Hong Kong spend effort compiling databases on haunted houses. ${ }^{8}$ Property websites maintain their databases by tracking local news and make their data publicly accessible online to attract browsing flow. After inquiring with real estate agents and market participants, we conduct a complete comparison of different internet portals of real estate companies and decide to draw on four of them with the longest lists. ${ }^{9}$ These data sources include for each incidence of unnatural death an event date, a description of the incident, and an address with varying degrees of detail. Appendix B1 gives a screenshot of one of these websites—Squarefoot—where the first page shows the tab called "Haunted House" and the second page gives the list of haunted houses. Appendix B2 gives a screenshot of another of these websites_-Spacious—where the first page shows the tab called "Haunted houses," the second page shows a spooky ghost, and the third page shows the exact location of a haunted house.

\footnotetext{
${ }^{8}$ Wary locals are not the only ones who the real estate companies target. They also target opportunistic non-locals. Coconuts (https://coconuts.co/hongkong/news/hong-kongs-haunted-apartments-go-half-price/) writes "Those looking to rent and buy in one of the world's most expensive cities for real estate can enjoy discounts of up to 50 percent if they're willing to stay in an apartment where a suicide or murder occurred."

9 The first is property.hk, the second is Squarefoot, the third is hk-compass.com and the fourth is Spacious. URLs of the four haunted house lists are http://www.property.hk/unlucky.php, http://www.squarefoot.com.hk/haunted/, http://www.hkcompass.com/badfile.php, and https://www.spacious.hk/en/hong-kong/resources/tragic-events, respectively. Data from the first and third links are in Chinese only. The second and fourth sites have English lists and are featured in a New York Times article: https://www.nytimes.com/2016/11/24/world/asia/hong-kong-haunted-units-app.html?_r=1. The English lists are subsets of their Chinese counterparts; therefore, we always use the Chinese list.
} 
As the focus of our current research is the most liquid 214 estates, we extract haunted houses only in these estates from the territory-wide databases described above using a name-matching algorithm. Further, we manually confirm that the haunted houses picked up by the name-matching algorithm do indeed belong to the 214 estates. Since the property information websites track the same news, there is overlap among their haunted houses databases. We remove duplicates before combining the four data sources. If two incidents happen within 4 days in the same estate, the deceased are of the same gender and have the same cause of death, one is considered as a duplicate, and hence dropped. Information which may help us to identify the detailed address is retained though. Finally, we obtain 898 records of haunted houses in the 214 liquid estates from 2000 to 2015.

One big challenge we face in this research is to locate the exact address where the tragic event occurred. Among the 898 incidents, the estate name is available for all. However, block number is available for $729(81 \%)$ of them, floor number is available for $434(48 \%)$ of them, and unit number is available only for a few of them. In some cases, the news mentions the transaction history of the haunted house, and so it is possible to look up the unit number from our transaction data. As of now, we have identified 165 addresses $(18 \%) .^{10}$

Panel A of Table 2 classifies haunted houses according to the type of unnatural death that caused the house to become haunted. Suicides are the major reason that a house becomes haunted $(73 \%$ of our sample of 898). The most common way to commit suicides is by jumping from a high elevation $(47.6 \%$ of our sample). Murder, on the other hand, accounts for only $2 \%$ of our sample. The residual $25 \%$ are

\footnotetext{
10 One reason why units are not identified all the time is a legal concern. Ghafoor, Spacious founder and CEO, is quoted: "There's a bit of a legal issue with this. For example, if you have a block of flats and somebody jumps off the roof, which individual unit is haunted? So we've got to be a bit careful about describing a haunted house as a specific unit because it leaves us open to being sued by a landlord. We only do that when it's very clear without a shadow of a doubt."

(http:/ / www.scmp.com/lifestyle/article/1872125/hong-kong-haunted-houses-online-map-who-died-where-boon-bargainhunters)
} 
classified as miscellaneous. This classification is important because, as we will see later, the negative spillover effect is greatest for murder, it exists for all other classifications as well.

Panel B of Table 2 documents that in our sample most haunted houses are in the New Territories. Finally, Panel C of Table 3 shows that the flow of haunted houses into our panel data set from 2000 to 2015 has been increasing over the years. There is a blip in 2013. This upward trend, but not the 2013 figure, can be explained by the fact that coverage of haunted houses in Hong Kong has been expanding over the years. In the next version of this paper, when we obtain all the addresses, these particular numbers may change.

\section{Spillover in Prices}

Table 3 reports the average price per square foot before and after a unit become haunted. Panel A shows the average price in HKD per square foot for transactions occurring one year before to one year after, whereas Panel B and C report the same for the period of two and three years before and after, respectively. To control for time-trends in prices we also report the average price per square foot in the same district in the same period, and provide a difference-in-differences estimate of the effect of haunted houses on the price per square feet.

We notice from Panel A that the affected unit increases in price by $14 \%$ from one year before to one year after the unit becomes haunted. This is much lower than for units in the district as a whole, where prices rise by $37 \%$ from one year before to one year after. The difference-in-difference is $-23 \%$. The ripple effect can be seen if we look at floors. The affected floor-here we remove the affected unit from the floor-decreases in price by 3\% from one year before to one year after the floor becomes haunted. This is lower than for units in the district as a whole, where prices rise by $2 \%$ from one year before to one year after. The difference-in-difference is $-5 \%$. The ripple effect is confirmed if we look at 
blocks. The affected block - here we remove the affected floor from the block - increases in price by $3 \%$ from one year before to one year after the floor becomes haunted. This is slightly lower than for units in the district as a whole, where prices rise by $4 \%$ from one year before to one year after. The differencein-difference is $-1 \% .^{11}$

The ripple effect continues to be seen in Panel B (two years before to two years afterwards). The difference-in-difference is $-29 \%$ for the unit, $-6 \%$ for the floor and $-1 \%$ for the block. The ripple effect continues to be seen in Panel C (three years before to three years afterwards). The difference-in-difference is $-31 \%$ for the unit, $-6 \%$ for the floor and $-1 \%$ for the block. In addition, by comparing Panels $A, B$ and C we observe that the prices drops are not temporary for the affected unit. They seem to recover, if at all, very slowly.

We now formally estimate the relationship between the price of houses and their characteristics using a hedonic regression. The main equation for estimating the haunted house discount is specified in Equation (1), where the dependent variable is the log price, $y_{i t}$ of apartment $i$ in year-month $t$ :

$$
y_{i t}=\alpha_{i}+\beta_{t}+\gamma^{\prime} X_{i}+\theta H_{i t-k}+\epsilon_{i t}
$$

where $\alpha_{i}$ captures apartment fixed effects, $\beta_{t}$ is a vector of year-month fixed effects, $X_{i}$ is a vector of apartment characteristics, and $H_{i t-k}$ is an indicator for a haunted house due to an unnatural death occurring in the last $k$ years before $t$. House characteristics that change over time in our sample are interior size and block age.

\footnotetext{
${ }^{11}$ Note that the average price per square foot in the affected district varies across units, floors, and blocks because we do not have the full address for all events in our sample. The average district price is therefore conditional on having information about which unit, floor, and block that are affected.
} 
The coefficient of interest in equation (1) is $\theta$. A negative $\theta$ reveals the discount for being haunted, and if negative, the value of $\theta$ reveals the percentage discount.

Table 4 shows the results of the above estimation. Table 4 is the main result of our paper. Column (1) reveals that the haunted unit drops in price by 19.7\% after it becomes haunted. Column (2) reveals that the affected floor-here the affected unit is excluded from the affected floor-drops in price by 4.7\% after it becomes haunted. Column (3) reveals that the affected block-here the affected floor is excluded from the affected block—drops in price by $2.7 \%$ after it becomes haunted. Column (4) reveals that the affected estate- - here the affected block is excluded from the affected estate-drops in price by $1.20 \%$ after it becomes haunted. Notice that all price drops, though statistically significant, diminish in magnitude as we move geographically outwards from the affected unit. This confirms the ripple effect we documented in Table 3.

The coefficients on size and age have the expected signs. Larger units are valued more; older units are valued less. The inclusion of apartment-fixed effects takes care of all time-invariant apartment characteristics. The year-month fixed effects controls for all market-wide demand and supply shocks over time.

Though Table 4 does show the ripple effect, it does not show whether the price drops are temporary or persistent. To do this we estimate Equation (2):

$$
y_{i t}=\alpha_{i}+\beta_{t}+\gamma^{\prime} X_{i}+\theta H_{i t-k}+\lambda * \text { Time } * H_{i t-k}+\epsilon_{i t},
$$

Equation (2) is the same as Estimation (1) with one extra term added: the interaction between Time and $H_{i t-k}$. Here Time is the difference between the transaction date and the death date, measured in 
years. The coefficient of interest in Equation (2) is $\lambda$. A positive $\lambda$ reveals that prices of discounted haunted houses recover over time, and if positive, the value of $\lambda$ reveals the speed of recovery.

Table 5 shows the results of the above estimation. Column (1) reveals that the haunted unit does not seem to recover at all. Notice that the coefficient on the interaction term is -0.0045 and statistically insignificant. Column (2) reveals that the affected floor-here the affected unit is excluded from the affected floor-does seem to recover about $0.32 \%$ per year after a price drop of $7.28 \%$. This recovery is slow as the estimated coefficient suggests that is takes more than 20 years for prices to recover. Column (3) reveals that the affected block-here the affected floor is excluded from the affected block- does seem to recover about $0.23 \%$ per year after a price drop of $5.6 \%$. This recovery is also slow and of similar magnitude to the recovery for the affected floor. Column (4) reveals that the affected estate-here the affected block is excluded from the affected estate-does seem to recover about $0.28 \%$ per year after a price drop of 3\%. This recovery is also slow. This confirms that the discounts are not temporary, a result suggested by the difference-in-difference estimates documented in Table 3.

It would be interesting to know which cause of death is associated with the largest drop in price, and which cause of death has the highest spillover effect on prices. ${ }^{12}$ The answers are given in Table 6 . The numbers in Table 6 come from the same estimation of Equation (1), except now the regressions are run for sub-samples related to cause of death.

Table 6 has two new results. First, Column 2 in Table 6 shows that murder has the most adverse effect on the price of a unit: the house price drops by $36.3 \%$. The number is statistically significant, which is remarkable considering that the sample size is only 21 . The second interesting new result is that jump

\footnotetext{
12 We quote from an article in the New York Times (Nov 14, 2016): "In Hong Kong, this is a big deal. Many people believe that living in a place where someone committed suicide or, worse, was murdered, brings all sorts of bad fortune. Those units, even years after such a death occurred, are discounted around 20 percent, sometimes 50 percent if the death was particularly gruesome."
} 
to death has the smallest effect on house prices amongst all the causes of death: the house price drops by $16.46 \%$. The number is statistically significant. What is interesting about this second new result is that jumping to death, as the jump often takes place from the roof of the block rather than from a unit, is expected to have less of an effect on the price of the unit or floor. It does. The other results in Table 6 are the same as before: all price drops for all types of unnatural deaths, though statistically significant, diminish in magnitude as we move geographically outwards from the affected unit. So the ripple effect occurs for all types of unnatural deaths.

\section{Disentangling Spillovers in Prices: Quality Channel vs. Price Pressure Channel}

To further our understanding of the spillover effects, we now examine the underlying channels. Prior literature recognizes that foreclosures of houses have negative spillovers on prices of neighboring houses because of two effects. The first effect is the quality channel, which occurs if foreclosures negatively affect the perceived quality of neighboring houses. The second effect is the price pressure channel, which occurs because potential buyers of houses in the neighborhood revise downwards their reservation prices when they observe discounted prices on foreclosed houses. Prior literature has not disentangled these two effects because the counterfactual effect on prices of neighboring houses, when the foreclosed property is not sold, is unobserved. Our research design allows us to disentangle these two effects, because the focal event is a unnatural death, rather than the sale of the property.

It is useful to develop a simple model to illustrate the two underlying channels. As all the units in an estate are fairly homogenous, we model the demand for houses, D, as a function of price, P:

$$
\mathrm{D}=\mathrm{H}+\mathrm{k}-\mathrm{cP}
$$


where $\mathrm{H}$ is an indicator variable equal to -a for a haunted house and 0 otherwise, $\mathrm{k}$ is a constant, and c is the price elasticity of demand. Intuitively k captures among other things, the quality of the house, while H captures the drop in quality due to the unnatural death.

We model the short-term supply for houses, S, as

$$
S=F+j
$$

where $\mathrm{F}$ is an indicator variable equal to $+\mathrm{b}$ if there is a forced sale and 0 otherwise, and $\mathrm{j}$ is a constant. Intuitively, F captures the additional supply effect due to forced sales, while $\mathrm{j}$ implies that the short-term supply of houses is constant.

The above formulation takes into account the conventional assumption that demand is negatively affected by price, while short-term supply is unaffected by price because it takes time for units to be listed and delisted from the supply pool. The new assumption is that haunted houses due to feng shui are perceived to be of low quality and so there is a drop in demand. Given these formulations of linear demand and supply curves, the equilibrium price of the house equals:

$$
P^{*}=\frac{[(H+k)-(F+j)]}{c}
$$

It follows that if a house becomes haunted, but the unit is not sold, the price of its neighbor's house drops by a/c (because $\delta \mathrm{P}^{*} / \delta \mathrm{H}=-\mathrm{a} / \mathrm{c}$ ). In Figure 4, this is the movement in price from $\mathrm{X}$ to $\mathrm{Y}$. We refer to this spillover effect as the "quality channel". If a house becomes haunted and the affected unit is sold, its neighbor's price drops by $(\mathrm{a}+\mathrm{b}) / \mathrm{c}$. In Figure 4, this is the movement in price from $\mathrm{X}$ to Z. So the spillover effect due to the "price pressure channel" is the movement in price from Y to Z, and this drop in price equals $\mathrm{b} / \mathrm{c}$ (because $\left.\delta \mathrm{P}^{*} / \delta \mathrm{F}=-\mathrm{b} / \mathrm{c}\right)$.. 
In our setting we can measure the spillover due to the "quality channel" - a/c - because we can observe the effect on price of neighboring houses before and after a unit becomes haunted, but the unit is not sold. Similarly, we can measure the spillover due to the "quality channel" plus the "price pressure channel" - $(\mathrm{a}+\mathrm{b}) / \mathrm{c}$ - because we can observe the effect on price of neighboring houses before and after a unit becomes haunted, and the unit is sold. The spillover caused by the "price pressure channel" - b/c - is then the difference between the latter spillover and the former spillover.

We estimate (4):

$$
y_{i t}=\alpha_{i}+\beta_{t}+\gamma^{\prime} X_{i}+\theta H_{i t-k}+\lambda * \text { Affected Unit Sold } * H_{i t-k}+\epsilon_{i t},
$$

Equation (4) is the same as estimation (1) with two crucial differences. First, one extra term is added: the interaction between Affected Unit Sold and $H_{i t-k}$. Here Affected Unit Sold takes a value of one if an affected unit is sold after the unnatural death. Second, we can only estimate Equation (4) for floors, blocks and estates, but not for units. The reason is obvious: if a unit does not sell after becoming haunted, we do not have a transaction price that can record a price drop. In other words, Equation (4) allows us to estimate only spillovers in prices.

The coefficients of interest in (4) are $\theta$ and $\lambda$. A negative $\theta$ reveals the percentage drop in prices of neighbouring houses that is due only to a change in perceived quality of the affected unit. A negative $\lambda$ reveals the percentage drop in prices of neighbouring houses that is due only to the price pressure channel because of a sale of the affected unit.

Table 7 shows the results of the above estimation. Column (1) reveals that the affected floor here the affected unit is excluded from the affected floor - sees a price drop of $5.3 \%$ after the floor becomes haunted. The interaction term between the indicator for haunted house and the indicator for 
whether the affected unit is sold is negative, but statistically insignificant. This reveals that for the floor the discount is coming from mainly the quality channel. Column (2) reveals that the affected block-here the affected floor is excluded from the affected block—-sees a general price drop of $2.3 \%$, and a further price drop of $3.5 \%$ if the affected unit is sold. This reveals that for the block the discount is coming from the both the quality and price pressure channels, but more from the price pressure channel. Column (3) reveals that the affected block — here the affected block is excluded from the affected estate — sees a price drop of $1.2 \%$, and a further price drop of $0.9 \%$ if the affected unit is sold. This reveals that for the estate the price drop is coming from the both the quality and price pressure channel, but less from the price pressure channel.

To the best of our knowledge, this is the first time in the empirical literature on spillovers in asset prices, a decomposition between the two channels for the spillover - the price pressure channel and the quality channel - has been achieved. Further, at least in the case of the Hong Kong private real estate market, we document that the quality channel is as important as the price pressure channel, if not more.

We explore this point more with another research design. We measure liquidity as the number of transactions that occur for a unit during a period divided by the number of transactions that occur for the same unit during our sample period of 16 years (2000 to 2015). If transactions are uniformly distributed over time, $1 / 16$, i.e. $6.25 \%$ of the transactions will take place each year. Deviations from $6.25 \%$ thus indicates a lower or higher fraction of transactions taking place in the specific time period. We refer to such deviations in the fraction of turnovers by year as excess transactions.

Table 8 reports the fraction of excess transactions taking place before and after a unit becomes haunted. Panel A shows the excess fraction of transactions in our sample occurring one year before to one year after death, whereas Panel B and C reports the same for the period of two and three years before 
and after death, respectively. To control for time-trends in market activity, we also report the excess fraction of transactions in the same district in the same period, and provide a difference-in-differences estimate of the effect of haunted houses on the excess fraction of excess transactions.

We notice from Panel A that the affected unit increases the excess fraction of sales by $8 \%$ from one year before to one year after the unit becomes haunted. This is much higher than for units in the district as a whole, where this excess fraction rises by only $0.1 \%$ from one year before to one year after. The difference-in-difference is $+8 \%$. A small ripple effect can be seen if we look at affected floors. The affected floor - here we again remove the affected unit from the floor-increases in excess fraction of sales by $0.9 \%$ from one year before to one year after the floor becomes haunted. This is higher for floors in the district as a whole, where this increase is only $0.2 \%$ from one year before to one year after. The difference-in-difference is $0.7 \%$. The ripple effect is not found if we look at blocks. The affected blockhere we remove the affected floor from the block-increases in excess fraction of sales by $0 \%$ from one year before to one year after the floor becomes haunted. This is slightly higher than for blocks in the district as a whole, where this increase is $-0.1 \%$ from one year before to one year after.

The small ripple continues to be seen in Panel B (two years before to two years afterwards). The difference-in-difference is $11.3 \%$ for the unit, $1 \%$ for the floor and $-0.3 \%$ for the block. The small ripple effect also continues to be seen in Panel C (three years before to three years afterwards). The differencein-difference is $10.6 \%$ for the unit, $0.7 \%$ for the floor and $0.6 \%$ for the block.

The ripple effect is not the most interesting result in Table 8. The most interesting result in Table 8 is how small the ripple effect is. Though liquidity rises for the haunted house after it becomes hauntedthis is likely to be driven by forced sales on average- there seems to a small spillover effect of liquidity. Units on the same floor and in the same block continue to sell at the same rate before or after the event. 
This provides further evidence that the price pressure channel is not the main mechanism for the spillover in prices.

\section{External Validity}

How relevant are our research findings for other parts of the world? In Hong Kong, the psychological component of the value of a house, given the beliefs of locals, is related to the principles of Feng Shui. An unnatural death, it is believed, causes excess negative energy, and impairs the value of a house. This naturally raises the question of the external validity of our findings.

We address this question in three ways. First, we search Factiva for newspaper articles from Australia, United Kingdom and Unites States using keywords related to unnatural deaths (murder, homicide, suicide, etc.) and real estate transactions (property, house, transaction, etc.). To ensure that we get an unbiased sample of newspaper articles, our search terms do not include keywords related to discount or price drops. We identify 101 newspaper articles featuring stories about the effect of unnatural death on house prices. For example, New York Times (Nov 24, 2016) interviewed Randall Bell, an economist who had consulted on the appraisals of notorious properties, like the homes of O. J. Simpson and Jon Benet Ramsey. According to Bell, the stigma can result in 25 percent lower prices. If we take an average of the quoted price effects in the 101 articles, we find that the value of affected units drops by 24 percent. The quoted discount is remarkably stable across countries. We find a 25 percent decline in Australia (18 articles), 25 percent in United Kingdom (20 articles), and 25 percent in United States (63 articles). In comparison, we find that affected units in Hong Kong decline by 20 percent follow. 
Second, we find that in the U.S. legal system, as in Hong Kong, it is illegal for a seller to hide the fact that the property being sold has a reputation of being haunted. ${ }^{13}$ Third, we find that web-based services like the website, www.diedinhouse.com, helps potential buyers in the U.S. to find out if anyone has died at a given address. This suggests that potential buyers find this information to be useful. Based on these three findings, we conclude that house price discounts due to unnatural deaths are relevant outside of Hong Kong.

\section{Conclusion}

Empirically it is difficult to convincingly conclude that house price drops are being caused by a negative shock in a neighboring house without completely ruling out that shocks to the local economy are affecting both. The first contribution of our study is that we exploit the unique institutional setting of Hong Kong's residential real estate to overcome this identification problem. We uncover a curious ripple effect of haunted houses on the prices of nearby houses. Prices drop on average $20 \%$ for units that become haunted, $5 \%$ for units on the same floor, $3 \%$ for units in the same block, and 1\% for units in the same estate. The ripple effect is strongest for murders. Price recovery is slow.

The second, and the more important contribution of our paper, is that since we observe that negative spillovers exist even if the haunted house is not sold, we can isolate the quality channel from the price pressure channel. We find that the quality channel contributes significantly to spillovers in assets prices.

${ }^{13}$ In the case Stambovsky v. Ackley, the Supreme Court of New York, Appellate Division ruled in 1991 that a seller must
disclose that a house has a reputation for being haunted when there is a fiduciary relationship or in cases of fraud or
misrepresentation, because such a reputation impairs the value of the house. (https://en.wikipedia.org/wiki/Haunted_house) 


\section{REFERENCES}

Acharya, V., S. T. Bharath, and A. Srinivasan. 2007. Does industry-wide distress affect defaulted firms? Evidence from creditor recoveries, Journal of Financial Economics 85, 787-821.

Andersen, S. and K. Nielsen. 2017. Fire Sales and House Prices: Evidence from Estate Sales Due to Sudden Death, Management Science, 63, 201-212.

Bernstein, S., E. Colonnelli, X. Giroud and B. Iverson. 2017. Bankruptcy Spillovers, NBER Working Paper No. w23162.

Campbell, J. Y., S. Giglio, and P. Pathak. 2011. Fire sales and House Prices, American Economic Review, 101, 2108-2131.

Coval, J., and E. Stafford. 2007. Asset fire sales (and purchases) in equity markets. Journal of Financial Economics 86 (2): 479-512.

Eckbo, E.B. and K. Thorburn. 2008. Automatic bankruptcy auctions and fire-sales, Journal of Financial Economics, 89, 404-422.

Gromb, D., and D. Vayanos. 2002. Equilibrium and welfare in markets with financially constrained arbitrageurs. Journal of Financial Economics 66 (2-3): 361-407.

Ivashina, V., and D. S. Scharfstein. 2010. Bank lending during the financial crisis of 2008. Journal of Financial Economics 97 (3): 319-38.

Kiyotaki, N., and J. Moore. 1997. Credit cycles. Journal of Political Economy 105 (2): 211-48.

Pulvino, T. 1998. Do Asset Fire Sales Exist? An Empirical Investigation of Commercial Aircraft Transactions, Journal of Finance 53 (3): 939-978.

Rossi-Hansberg, E., P. D. Sarte and R. Owens. 2010. Housing Externalities, Journal of Political Economy, 118, 485-535.

Shleifer, A. and R. Vishny. 2011. Fire Sales in Finance and Macroeconomics, Journal of Economic Perspectives, 25, 29-48. 


\section{Table 1, Descriptive statistics}

We report descriptive statistics for all transactions, and transactions in estates that are classified as liquid or not, respectively. A liquid estate is defined as estates with 1,000 or more transactions over our sample period, equivalent to around 5 transactions per month. Panel A reports transaction characteristics: Price is in million HKD (one USD equals $7.78 \mathrm{HKD}$ ), Size is measured in square feet (one square meter equals 10.76 square feet), Price per square feet is in $\mathrm{HKD}$, and block age is measured in years. Panels $\mathrm{B}, \mathrm{C}$, and $\mathrm{D}$ report the distribution of transactions on territory (i.e. region), year, and quarter of year, respectively. $* * *$ denotes significance at the $1 \%$ level.

\begin{tabular}{|c|c|c|c|c|}
\hline & \multirow[t]{2}{*}{ All } & \multicolumn{2}{|c|}{ Liquid estate } & \multirow{2}{*}{$\begin{array}{r}\text { Difference } \\
\text { (1)-(2) }\end{array}$} \\
\hline & & $\begin{array}{l}\text { Yes } \\
\text { (1) }\end{array}$ & $\begin{array}{l}\text { No } \\
\text { (2) }\end{array}$ & \\
\hline \multicolumn{5}{|c|}{ A. Transaction characteristics } \\
\hline Price (million HKD) & 4.22 & 3.88 & 4.67 & $0.75^{* * *}$ \\
\hline Size (square feet) & 594.3 & 589.0 & 603.5 & $-12.6^{* * *}$ \\
\hline Price per square feet (HKD) & $6,393.2$ & $6,094.3$ & 6,916.9 & $-772.3^{* * *}$ \\
\hline Block age (years) & 15.2 & 10.4 & 21.6 & $-11.1^{* * *}$ \\
\hline \multicolumn{5}{|l|}{ B. Territory (\%) } \\
\hline Hong Kong Island & 23.0 & 11.9 & 37.6 & \\
\hline Kowloon & 28.6 & 23.3 & 35.6 & \\
\hline New Territories & 48.4 & 64.8 & 26.8 & \\
\hline \multicolumn{5}{|l|}{ C. Year } \\
\hline 2000 & 52,015 & 30,268 & 21,747 & \\
\hline 2001 & 60,216 & 35,998 & 24,218 & \\
\hline 2002 & 58,496 & 37,358 & 21,138 & \\
\hline 2003 & 60,557 & 39,535 & 21,022 & \\
\hline 2004 & 84,092 & 51,849 & 32,243 & \\
\hline 2005 & 80,998 & 47,515 & 33,483 & \\
\hline 2006 & 66,214 & 36,094 & 30,120 & \\
\hline 2007 & 107,122 & 60,975 & 46,147 & \\
\hline 2008 & 70,668 & 39,581 & 31,087 & \\
\hline 2009 & 100,855 & 57,212 & 43,643 & \\
\hline 2010 & 110,133 & 61,779 & 48,354 & \\
\hline 2011 & 67,341 & 36,302 & 31,039 & \\
\hline 2012 & 68,629 & 38,987 & 29,642 & \\
\hline 2013 & 39,803 & 22,028 & 17,775 & \\
\hline 2014 & 53,581 & 30,173 & 23,408 & \\
\hline 2015 & 43,628 & 21,015 & 22,613 & \\
\hline \multicolumn{5}{|l|}{ D. Quarter } \\
\hline First & 288,199 & 167,193 & 121,006 & \\
\hline Second & 290,003 & 165,192 & 124,811 & \\
\hline Third & 277,780 & 160,804 & 116,976 & \\
\hline Fourth & 268,366 & 153,480 & 114,886 & \\
\hline $\mathrm{N}$ & $1,124,348$ & 646,669 & 477,679 & \\
\hline
\end{tabular}




\section{Table 2, Sample of haunted houses}

We report the composition of the sample of haunted houses in liquid estates between 2000 and 20015. A house becomes haunted if a murder, suicide, or some other unnatural death occurs. Panel A reports the cause of death, as well as sub-causes for suicides. Panels B, and $\mathrm{C}$ report the distribution of unnatural deaths on territory (i.e. region), and year.

\begin{tabular}{|c|c|c|}
\hline & $\mathbf{N}$ & $\%$ \\
\hline \multicolumn{3}{|l|}{ A. Cause of deaths } \\
\hline Murder & 21 & $2.3 \%$ \\
\hline Suicide & 656 & $73.1 \%$ \\
\hline - Hanging & 74 & $8.2 \%$ \\
\hline - Jump to death & 427 & $47.6 \%$ \\
\hline - Other suicides & 155 & $17.3 \%$ \\
\hline Other & 221 & $24.7 \%$ \\
\hline \multicolumn{3}{|l|}{ B. Territory } \\
\hline Hong Kong Island & 194 & $21.6 \%$ \\
\hline Kowloon & 218 & $24.3 \%$ \\
\hline New Territories & 486 & $54.1 \%$ \\
\hline \multicolumn{3}{|l|}{ C. Year } \\
\hline 2000 & 26 & $2.9 \%$ \\
\hline 2001 & 39 & $4.3 \%$ \\
\hline 2002 & 31 & $3.5 \%$ \\
\hline 2003 & 53 & $5.9 \%$ \\
\hline 2004 & 45 & $5.0 \%$ \\
\hline 2005 & 30 & $3.3 \%$ \\
\hline 2006 & 37 & $4.1 \%$ \\
\hline 2007 & 41 & $4.6 \%$ \\
\hline 2008 & 59 & $6.6 \%$ \\
\hline 2009 & 59 & $6.6 \%$ \\
\hline 2010 & 62 & $6.9 \%$ \\
\hline 2011 & 45 & $5.0 \%$ \\
\hline 2012 & 87 & $9.7 \%$ \\
\hline 2013 & 108 & $12.0 \%$ \\
\hline 2014 & 99 & $11.0 \%$ \\
\hline 2015 & 77 & $8.6 \%$ \\
\hline $\mathrm{N}$ & 898 & $100 \%$ \\
\hline
\end{tabular}




\section{Table 3, Difference-in-differences estimate of haunted houses on price per square feet}

This table reports the average price per square feet before and after a unit becomes haunted. Panel A shows the average price per square feet for transactions occurring one year before to one year after, whereas Panel B and C reports the same for the period of two and three years before and after, respectively. We report the effect of affected units, units on the affected floor (excluding the affected unit), and for units in the affected block (excluding the affected floor). To control for time-trends in prices we also report the average price per square foot in the same district, and provide a difference-in-differences estimate of the effect of haunted houses on the price per square feet.

\begin{tabular}{|c|c|c|c|c|c|c|c|c|c|}
\hline \multirow[t]{3}{*}{ Window } & \multicolumn{3}{|c|}{ Unit } & \multicolumn{3}{|c|}{ Floor } & \multicolumn{3}{|c|}{ Block } \\
\hline & \multicolumn{2}{|c|}{ Price per square feet } & \multirow{2}{*}{$\begin{array}{c}\% \\
\text { Difference }\end{array}$} & \multicolumn{2}{|c|}{ Price per square feet } & \multirow{2}{*}{$\begin{array}{c}\% \% \\
\text { Difference } \\
\end{array}$} & \multicolumn{2}{|c|}{ Price per square feet } & \multirow{2}{*}{$\begin{array}{c}\% \\
\text { Difference }\end{array}$} \\
\hline & Haunted & District & & Haunted & District & & Haunted & District & \\
\hline \multicolumn{10}{|c|}{ A. One year before to one year after } \\
\hline Before & 4,162 & 4,013 & $-4 \%$ & 4,168 & 4,648 & $12 \%$ & 4,452 & 4,644 & $4 \%$ \\
\hline After & 4,725 & 5,490 & $16 \%$ & 4,036 & 4,738 & $17 \%$ & 4,600 & 4,839 & $5 \%$ \\
\hline Difference & $14 \%$ & $37 \%$ & $-23 \%$ & $-3 \%$ & $2 \%$ & $-5 \%$ & $3 \%$ & $4 \%$ & $-1 \%$ \\
\hline \multicolumn{10}{|c|}{ B. Two years before to two years after } \\
\hline Before & 4,257 & 3,955 & $-7 \%$ & 4,078 & 4,540 & $11 \%$ & 4,388 & 4,582 & $4 \%$ \\
\hline After & 4,605 & 5,407 & $17 \%$ & 4,069 & 4,787 & $18 \%$ & 4,590 & 4,819 & $5 \%$ \\
\hline Difference & $8 \%$ & $37 \%$ & $-29 \%$ & $0 \%$ & $5 \%$ & $-6 \%$ & $5 \%$ & $5 \%$ & $-1 \%$ \\
\hline \multicolumn{10}{|c|}{ C. Three years before to three years after } \\
\hline Before & 4,808 & 4,167 & $-13 \%$ & 4,106 & 4,546 & $11 \%$ & 4,338 & 4,517 & $4 \%$ \\
\hline After & 4,213 & 4,930 & $17 \%$ & 3,989 & 4,711 & $18 \%$ & 4,587 & 4,828 & $5 \%$ \\
\hline Difference & $-18 \%$ & $18 \%$ & $-31 \%$ & $-3 \%$ & $4 \%$ & $-6 \%$ & $6 \%$ & $7 \%$ & $-1 \%$ \\
\hline
\end{tabular}




\section{Table 4. Spillover effects of haunted houses on price}

This table shows the ripple effect of haunted houses on prices. The dependent variable is log. of the transaction price in million HKD. In Column 1, 2, 3, and 4 the sample consists of transactions in estates where the affected unit, floor, block, and estate are known, respectively. To capture the ripple effect affected units are excluded in Column 2 to 4, units in affected floors are excluded in Column 3 and 4, while unit in the affected block are excluded in Column 4. Haunted house is an indicator taking the value of one if the transaction involves an affected unit (Column 1), units on the floor of the affected unit (Column 2), units in the block of the affected unit (Column 3), and units in the estate of the affected unit (Column 4). Size is the size of the unit measured in square feet. Age is the block age measured years. All specifications include unit fixed-effects and year-month fixed effects.

\begin{tabular}{lcccc}
\hline & $\begin{array}{c}\text { Unit } \\
(\mathbf{1})\end{array}$ & $\begin{array}{c}\text { Floor } \\
\mathbf{( 2 )}\end{array}$ & $\begin{array}{c}\text { Block } \\
\mathbf{( 3 )}\end{array}$ & $\begin{array}{c}\text { Estate } \\
\mathbf{( 4 )}\end{array}$ \\
\hline \multirow{2}{*}{ Haunted house } & & & & \\
& $-0.1970^{* * *}$ & $-0.0466^{* * *}$ & $-0.0271^{* * *}$ & $-0.0120^{* * *}$ \\
Size & $(0.049)$ & $(0.0015)$ & $(0.0019)$ & $(0.0014)$ \\
& $0.0016^{* * *}$ & $0.0014^{* * *}$ & $0.0014^{* * *}$ & $0.0014^{* * *}$ \\
Age & $(0.0001)$ & $(0.0001)$ & $(0.0001)$ & $(0.0001)$ \\
& $-0.0116^{* * *}$ & $-0.0171^{* * *}$ & $-0.0186^{* * *}$ & $-0.0213^{* * *}$ \\
Unit fixed-effects & $(0.0004)$ & $(0.0003)$ & $(0.0003)$ & $(0.0006)$ \\
Year-month fixed effects & Yes & Yes & Yes & Yes \\
Adj. R-squared & Yes & Yes & Yes & Yes \\
N & 0.988 & 0.976 & 0.976 & 0.975 \\
& 151,237 & 323,586 & 324,025 & 199,516 \\
\hline
\end{tabular}




\section{Table 5. Decay in spillover effects}

This table estimates the decay in the ripple effect of haunted houses on transaction prices. The dependent variable is log. of the transaction price in million HKD. In Column 1, 2, 3, and 4 the sample consists of transactions in estates where the affected unit, floor, block, and estate are known, respectively. To capture the ripple effect affected units are excluded in Column 2 to 4, units in affected floors are excluded in Column 3 and 4, while unit in the affected block are excluded in Column 4. Haunted house is an indicator taking the value of one if the transaction involves an affected unit (Column 1), units on the floor of the affected unit (Column 2), units in the block of the affected unit (Column 3), and units in the estate of the affected unit (Column 4). Time is the difference between the transaction date and the death date, measured in years. Size is the size of the unit measured in square feet. Age is the block age measured years. All specifications include unit fixed-effects and year-month fixed effects.

\begin{tabular}{lcccc}
\hline & $\begin{array}{c}\text { Unit } \\
(\mathbf{1})\end{array}$ & $\begin{array}{c}\text { Floor } \\
\mathbf{( 2 )}\end{array}$ & $\begin{array}{c}\text { Block } \\
\mathbf{( 3 )}\end{array}$ & $\begin{array}{c}\text { Estate } \\
\mathbf{( 4 )}\end{array}$ \\
\hline Haunted house & & & & \\
& $-0.1626^{* * *}$ & $-0.0728^{* * *}$ & $-0.05569^{* * *}$ & $-0.0296^{* * *}$ \\
Haunted house * Time & $(0.0539)$ & $(0.0015)$ & $(0.0016)$ & $(0.0010)$ \\
Size & -0.0045 & $0.0032^{* * *}$ & $0.0023^{* * *}$ & $0.0028^{* * *}$ \\
& $(0.0054)$ & $(0.0011)$ & $(0.0002)$ & $(0.0001)$ \\
Age & $0.0016^{* * *}$ & $0.0014^{* * *}$ & $0.0014^{* * *}$ & $0.0014^{* * *}$ \\
& $(0.0001)$ & $(0.0001)$ & $(0.0001)$ & $(0.0001)$ \\
Unit fixed-effects & $-0.0116^{* * *}$ & $-0.0171^{* * *}$ & $-0.0166^{* * *}$ & $-0.0190^{* * *}$ \\
Year-month fixed effects & $(0.0004)$ & $(0.0004)$ & $(0.0003)$ & $(0.0003)$ \\
Adj. R-squared & Yes & Yes & Yes & Yes \\
N & Yes & Yes & Yes & Yes \\
& 0.988 & 0.976 & 0.976 & 0.975 \\
\hline
\end{tabular}




\section{Table 6, Cause of death and spillover effects}

This table shows the ripple effect of haunted houses on transaction prices for various causes of death. The dependent variable is log. of the transaction price in million HKD. Each cell in the table reports the coefficient on haunted house for all deaths in Column 1, murder in column 2, jumps to deaths in Column 3, death by hanging in Column4, other suicides in Column 5 and unclassified deaths in column 6. In Row 1, 2, 3, and 4 the sample consists of transactions in estates where the affected unit, floor, block, and estate are known, respectively. To capture the ripple effect affected units are excluded in Row 2 to 4, units in affected floors are excluded in Row 3 and 4, while unit in the affected block are excluded in Row 4. The table reports the coefficient on Haunted house, which is an $\mathrm{i}$ indicator taking the value of one if the transaction involves an affected unit (Row 1), units on the floor of the affected unit (Row 2), units in the block of the affected unit (Row 3), and units in the estate of the affected unit (Row 4). All specifications include controls for size and age as well as unit fixed-effects and year-month fixed effects.

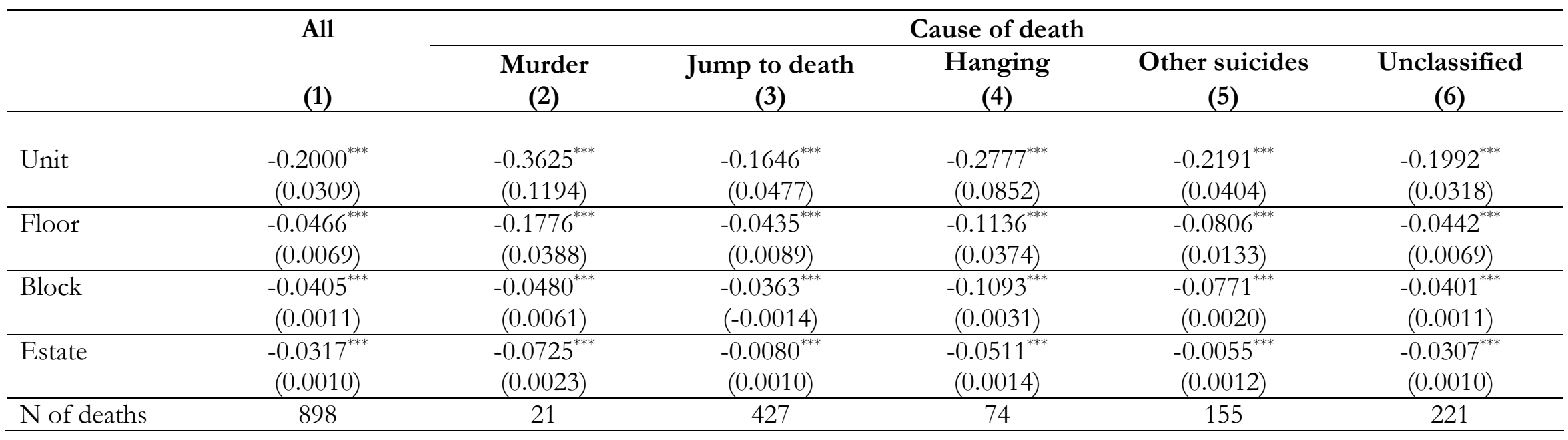




\section{Table 7. Price pressure and spillover effects}

This table examines whether the ripple effect of haunted houses on transaction prices is driven by price pressure from the affected unit. The dependent variable is log. of the transaction price in million HKD. In Column 1, 2, and 3, the sample consists of transactions in estates where the affected floor, block, and estate are known, respectively. To capture the ripple effect affected units are excluded in Column 1 to 3 , units on affected floors are excluded in Column 2 and 3, while units in the effected block is excluded in Column 3. Haunted house is an indicator taking the value of one if the transaction involves the floor pf the affected unit (Column 1), the block of the affected unit (Column 2), and the estate of the affected unit (Column 3). Affected unit sold takes the value one if the affected unit is sold before the transaction. Size is the size of the unit measured in square feet. Age is the block age measured years. All specifications include unit fixed-effects and year-month fixed effects.

\begin{tabular}{lccc}
\hline & $\begin{array}{c}\text { Floor } \\
\mathbf{( 1 )}\end{array}$ & $\begin{array}{c}\text { Block } \\
\mathbf{( 2 )}\end{array}$ & $\begin{array}{c}\text { Estate } \\
\mathbf{( 3 )}\end{array}$ \\
\hline Haunted house & & & $-0.0121^{* * *}$ \\
& $-0.0527^{* * *}$ & $-0.0226^{* * *}$ & $(0.0014)$ \\
Haunted house * Affected unit sold & $(0.0016)$ & $(0.0020)$ & $-0.0093^{* * *}$ \\
& 0.0070 & $-0.0350^{* * *}$ & $(0.0001)$ \\
Size & $(0.0530)$ & $(0.0049)$ & $0.0014^{* * *}$ \\
Age & $0.0014^{* * *}$ & $0.0014^{* * *}$ & $(0.001)$ \\
& $(0.0001)$ & $(0.0001)$ & $-0.0213^{* * *}$ \\
Unit fixed-effects & $-0.0171^{* * *}$ & $-0.0186^{* * *}$ & $(0.0006)$ \\
Year-month fixed effects & $(0.0003)$ & $(0.0003)$ & Yes \\
Adj. R-squared & & & Yes \\
N & Yes & Yes & 0.976 \\
\end{tabular}




\section{Table 8, Difference-in-differences estimate of haunted houses on liquidity (measured by excess fraction of transactions)}

This table reports the fraction of excess transactions taking place before and after a unit become haunted. Panel A shows the excess fraction of transactions in our sample occurring one year before to one year after death, whereas Panel B and C reports the same for the period of two and three years before and after death, respectively. We report the on the liquidity of the affected units, affected units on the floor of (but excluding) the affected unit, and for units in the block of (but excluding) affected unit and floor. To control for time-trends in prices we also report the excess fraction of transactions in the same district in the same time period, and provide a difference-in-differences estimate of the effect of haunted houses on the fraction of excess transactions. Excess transactions are calculated relative to the uniform distribution over time, where $6.25 \%$ of the transactions will take place each year. Deviations from $6.25 \%$ thus indicate a lower or higher fraction of excess transactions taking place in the specific time period.

\begin{tabular}{|c|c|c|c|c|c|c|c|c|c|}
\hline \multirow[t]{3}{*}{ Window } & \multicolumn{3}{|c|}{ Unit } & \multicolumn{3}{|c|}{ Floor } & \multicolumn{3}{|c|}{ Block } \\
\hline & \multicolumn{2}{|c|}{ Excess fraction of sales } & \multirow{2}{*}{$\begin{array}{c}\% \\
\text { Difference } \\
\end{array}$} & \multicolumn{2}{|c|}{ Excess fraction of sales } & \multirow{2}{*}{$\begin{array}{c}\% \\
\text { Difference } \\
\end{array}$} & \multicolumn{2}{|c|}{ Excess fraction of sales } & \multirow{2}{*}{$\begin{array}{c}\% \% \\
\text { Difference }\end{array}$} \\
\hline & Haunted & District & & Haunted & District & & Haunted & District & \\
\hline \multicolumn{10}{|c|}{ A. One year before to one year after } \\
\hline Before & $-1.9 \%$ & $0.3 \%$ & $-2.1 \%$ & $-1.7 \%$ & $-0.1 \%$ & $-1.6 \%$ & $0.5 \%$ & $0.1 \%$ & $0.4 \%$ \\
\hline After & $6.2 \%$ & $0.4 \%$ & $5.8 \%$ & $-0.8 \%$ & $0.2 \%$ & $-0.9 \%$ & $0.5 \%$ & $-0.1 \%$ & $0.5 \%$ \\
\hline Difference & $8.0 \%$ & $0.1 \%$ & $8.0 \%$ & $0.9 \%$ & $0.2 \%$ & $0.7 \%$ & $0.0 \%$ & $-0.1 \%$ & $-0.1 \%$ \\
\hline \multicolumn{10}{|c|}{ B. Two years before to two years after } \\
\hline Before & $-5.4 \%$ & $0.3 \%$ & $-5.7 \%$ & $-3.2 \%$ & $-0.1 \%$ & $-3.1 \%$ & $0.4 \%$ & $0.1 \%$ & $0.3 \%$ \\
\hline After & $5.3 \%$ & $-0.3 \%$ & $5.6 \%$ & $-2.0 \%$ & $0.1 \%$ & $-2.1 \%$ & $-0.1 \%$ & $-0.7 \%$ & $0.6 \%$ \\
\hline Difference & $10.7 \%$ & -0.6 & $11.3 \%$ & $1.2 \%$ & $0.2 \%$ & $1.0 \%$ & $-0.5 \%$ & $-0.8 \%$ & $-0.3 \%$ \\
\hline \multicolumn{10}{|c|}{ C. Three years before to three years after } \\
\hline Before & $-7.2 \%$ & $0.5 \%$ & $-7.6 \%$ & $-4.6 \%$ & $-0.4 \%$ & $-4.2 \%$ & $0.4 \%$ & $0.2 \%$ & $0.2 \%$ \\
\hline After & $2.9 \%$ & $-0.2 \%$ & $3.0 \%$ & $-4.1 \%$ & $-0.6 \%$ & $-3.5 \%$ & $-1.3 \%$ & $-2.1 \%$ & $0.8 \%$ \\
\hline Difference & $10.0 \%$ & $-0.6 \%$ & $10.6 \%$ & $-0.5 \%$ & $-0.2 \%$ & $0.7 \%$ & $-1.6 \%$ & $-2.2 \%$ & $0.6 \%$ \\
\hline
\end{tabular}




\section{Figure 1, Cumulative number of transactions per year by illiquidity rank}

This figure shows the cumulative number of transaction per year sorted by the illiquidity rank of the estate. The most liquid estate has an illiquidity rank of zero, while the least liquid estate has a value of one. The red line is the cut-off between liquid and illiquid estates. A liquid estate is defined as estates with 1,000 or more transactions over our sample period, equivalent to around 5 transactions per month.

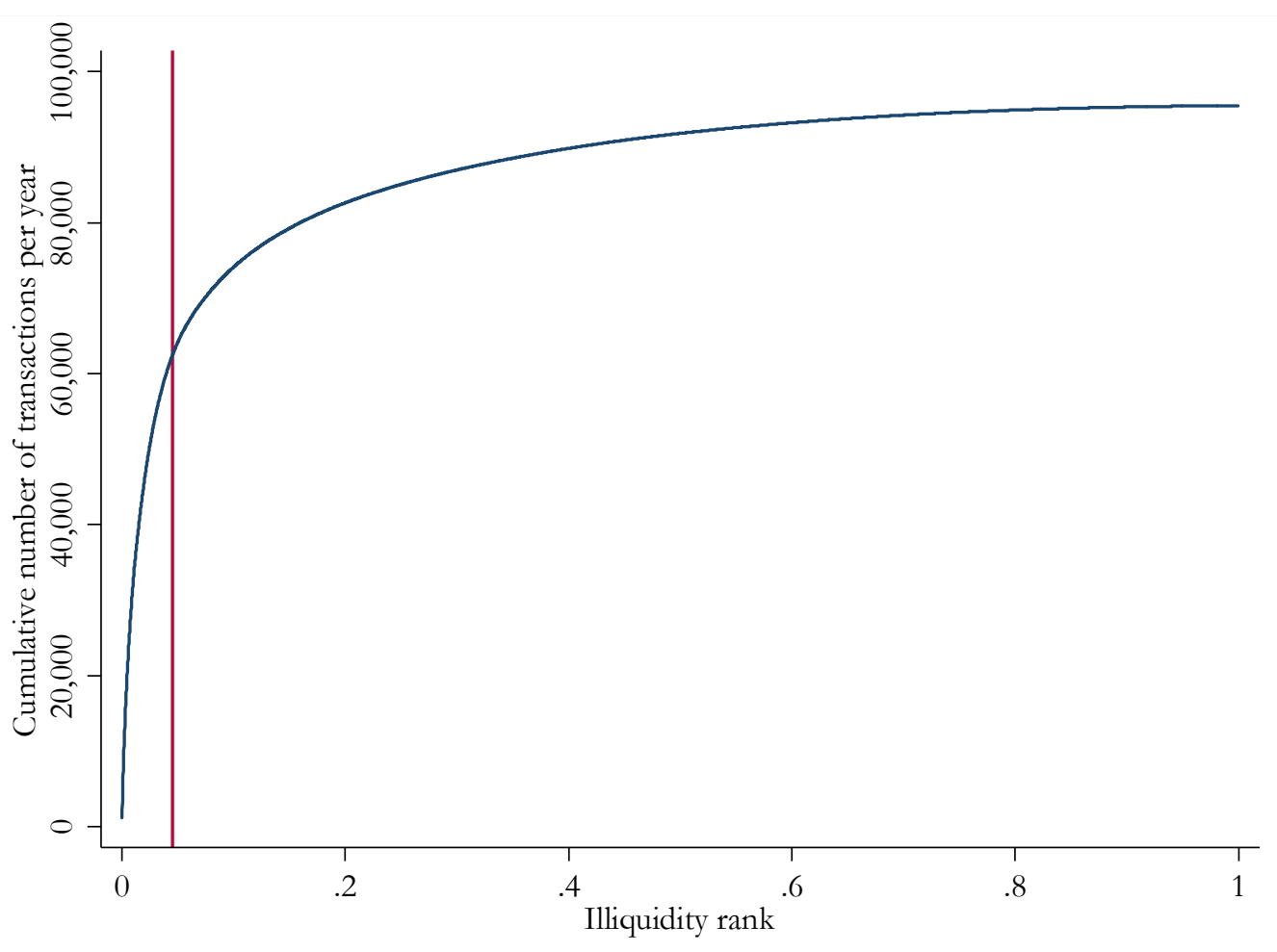




\section{Figure 2, Market share of liquid estates}

This figure shows the market share of liquid estates between 2000 and 2015. A liquid estate is defined as estates with 1,000 or more transactions over our sample period, equivalent to around 5 transactions per month. We calculate the market share in liquid estates based on the number and value of transactions in each year.

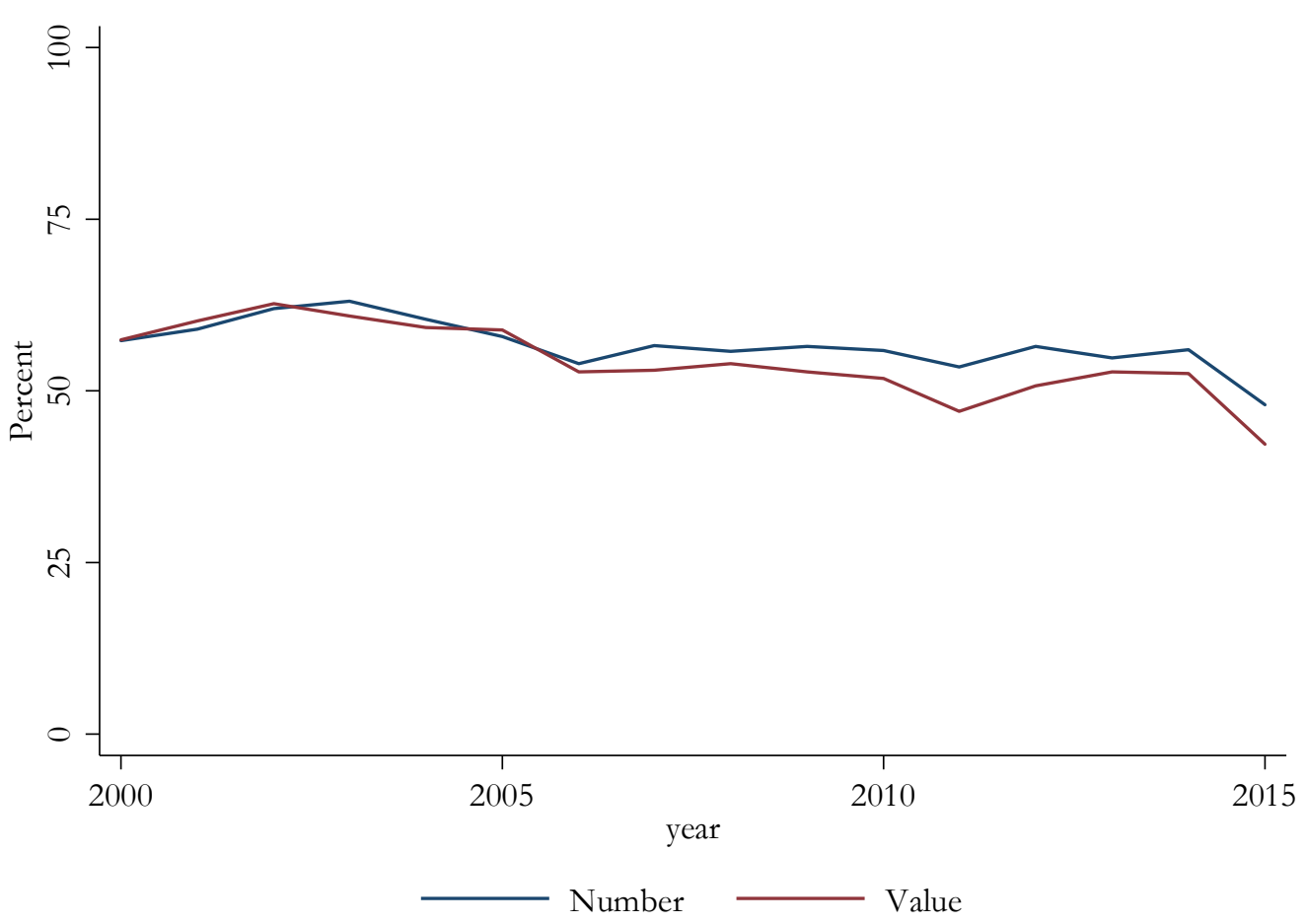


Figure 3, House price development, 2000-2015

This figure shows the average price per square for liquid and illiquid estates feet between 2000 and 2015. A liquid estate is defined as estates with 1,000 or more transactions over our sample period, equivalent to around 5 transactions per month.

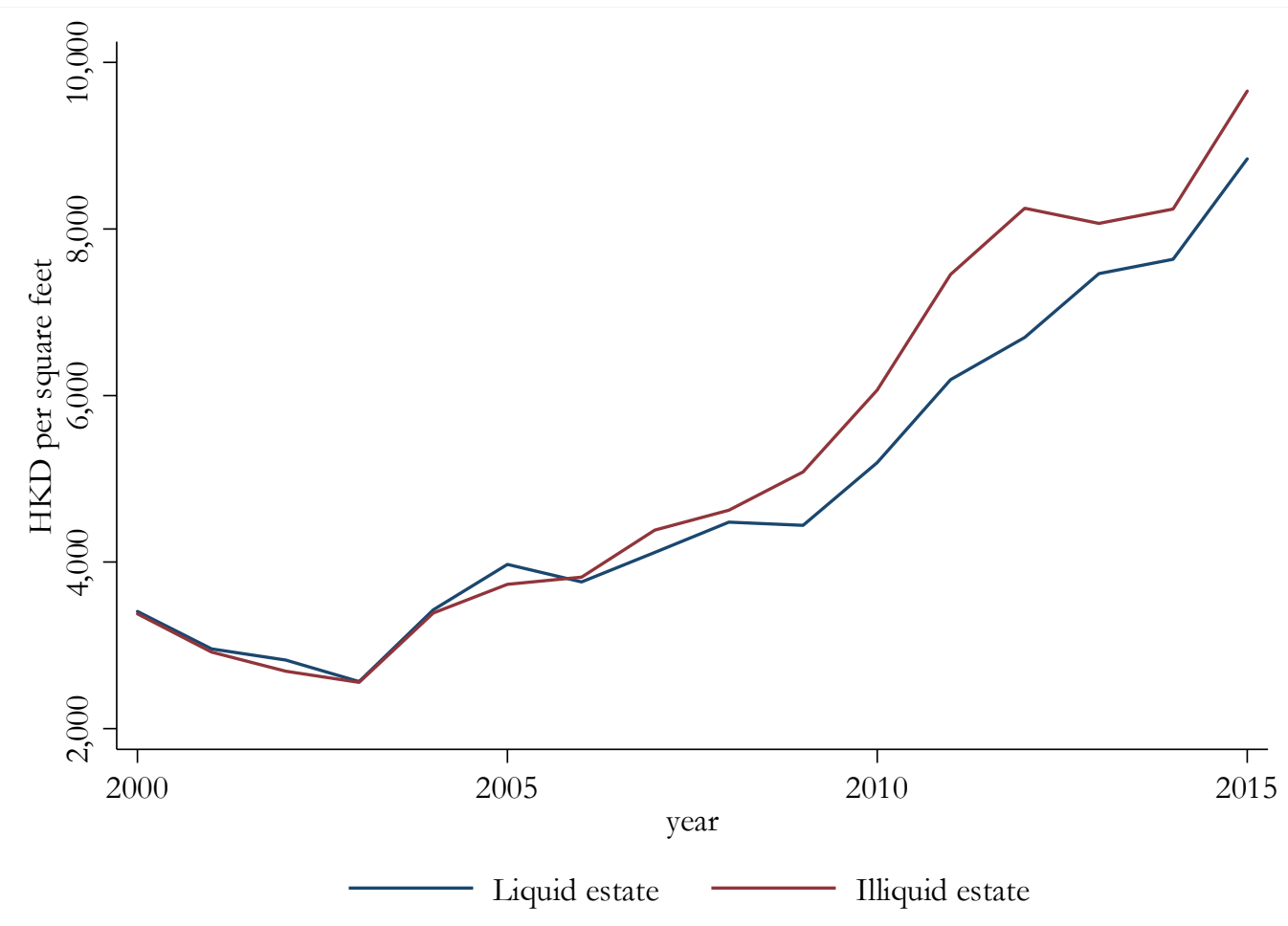




\section{Figure 4, Disentangling spillovers in prices: Quality channel vs. price pressure channel}

This figure illustrates the decomposition of the spillover in prices into the quality channel and the price pressure channel. Before a unit becomes haunted, point $\mathrm{X}$ shows the price of its neighbour's house. The price of the neighbour's house drops to point $\mathrm{Y}$ when the unit becomes haunted, but is not sold. The price of the neighbour's house drops to point $Z$ when the unit becomes haunted and is sold. The vertical distance from $X$ to $\mathrm{Z}$ is the spillover in prices, which is decomposed into the effect from the quality channel ( $\mathrm{X}$ to $\mathrm{y}$ ) and the effect from the price pressure channel (Y to Z)

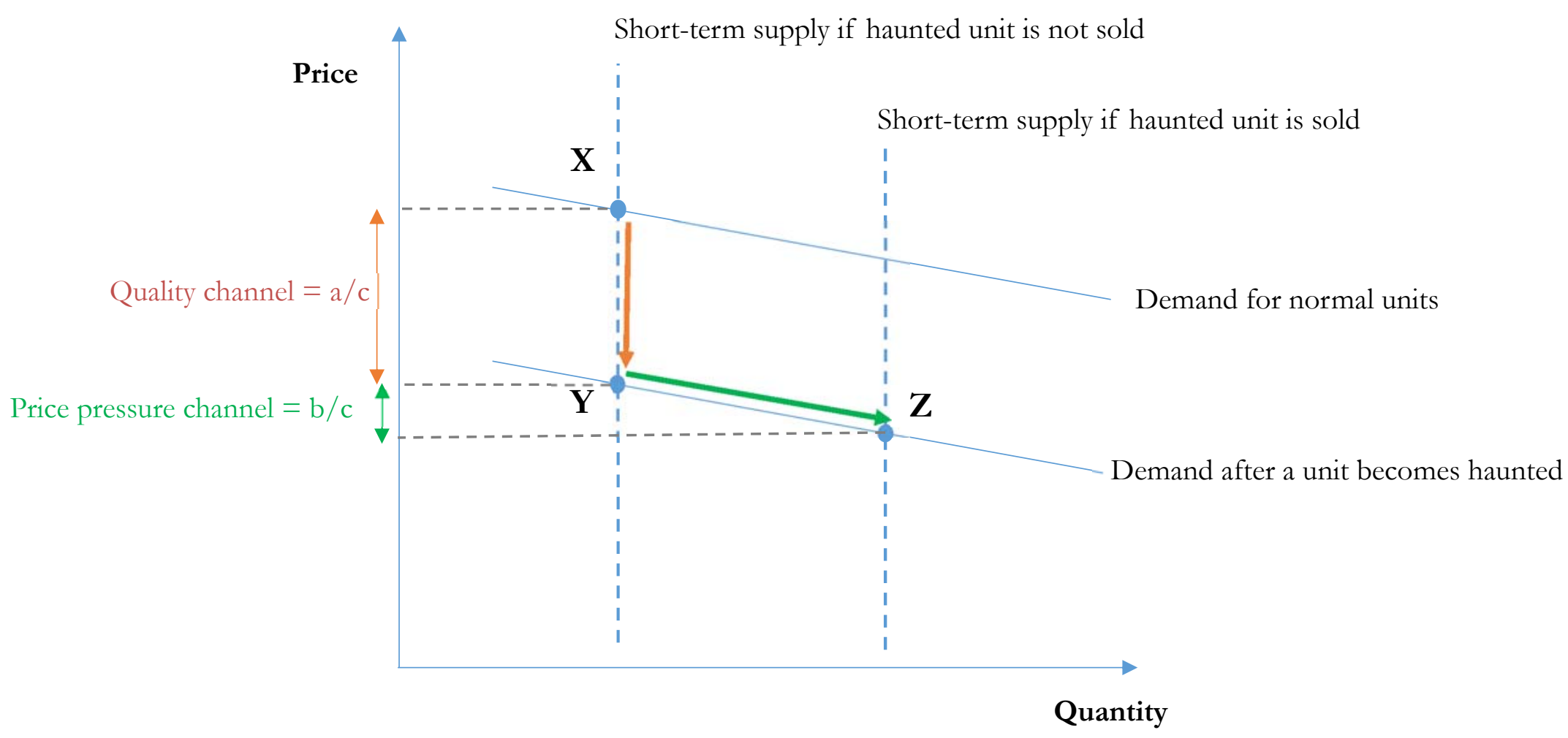




\section{Appendix A1: The 18 Districts of Hong Kong}

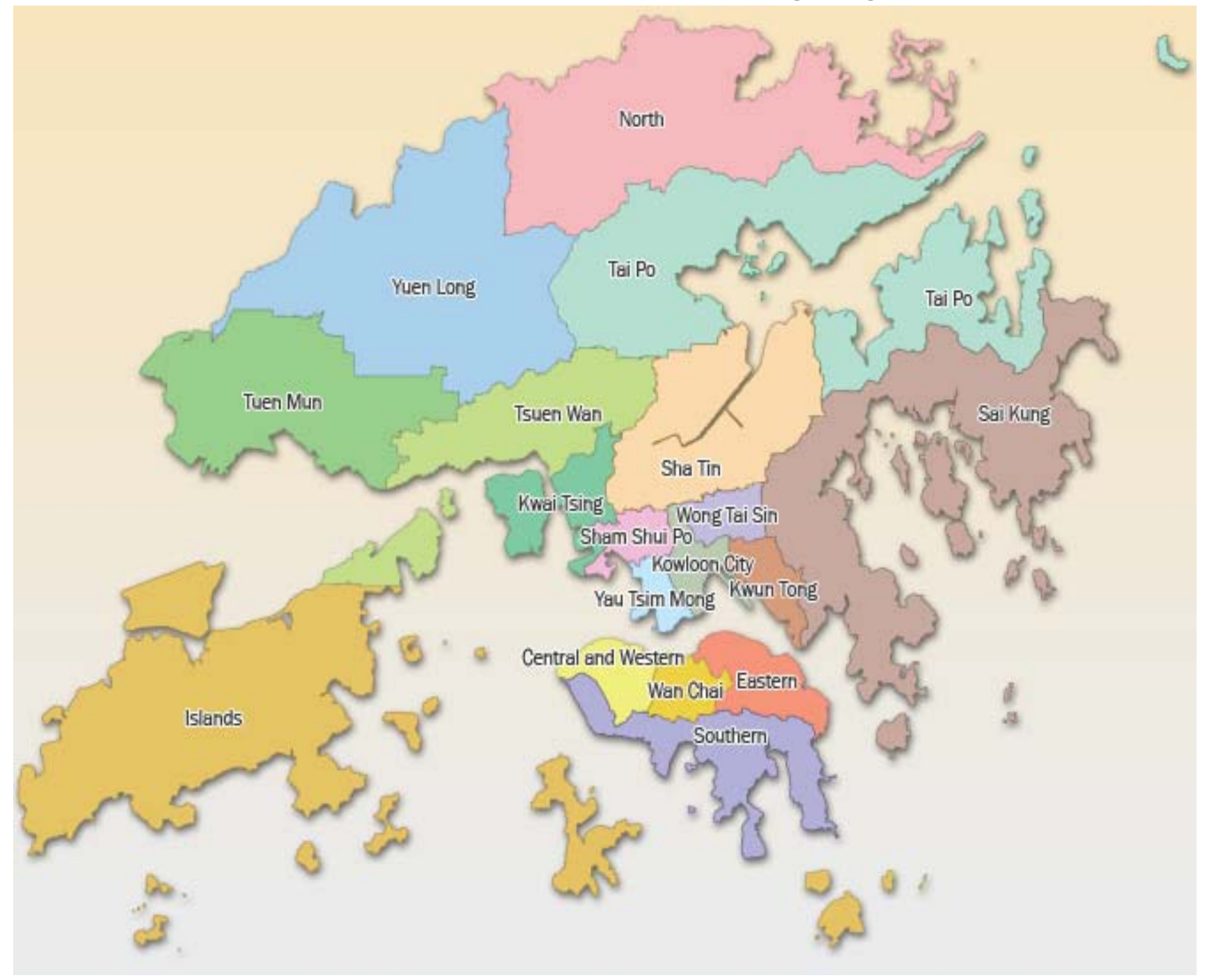


Appendix A2: Dawning Views in Fanling, North District, New Territories
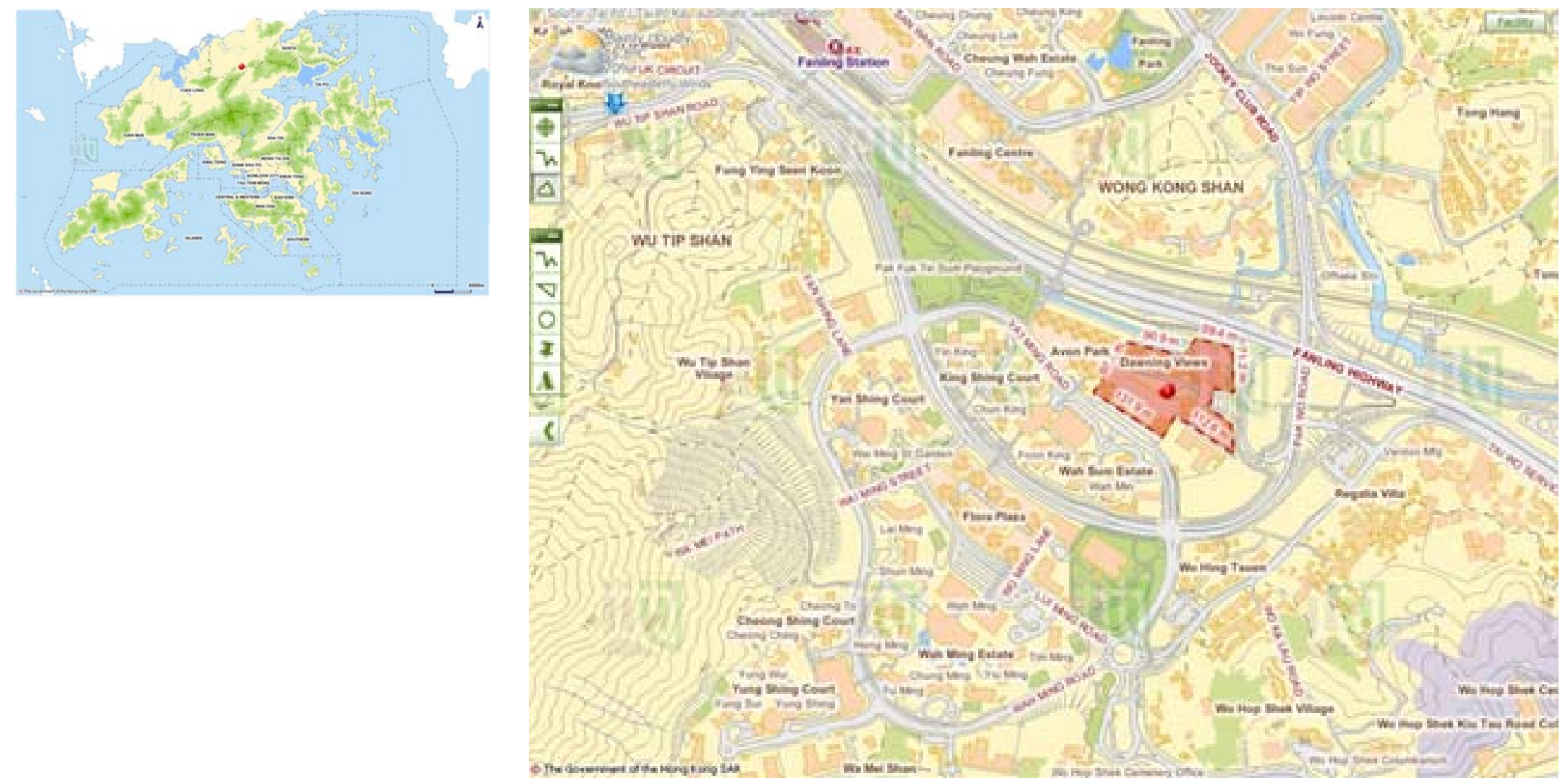


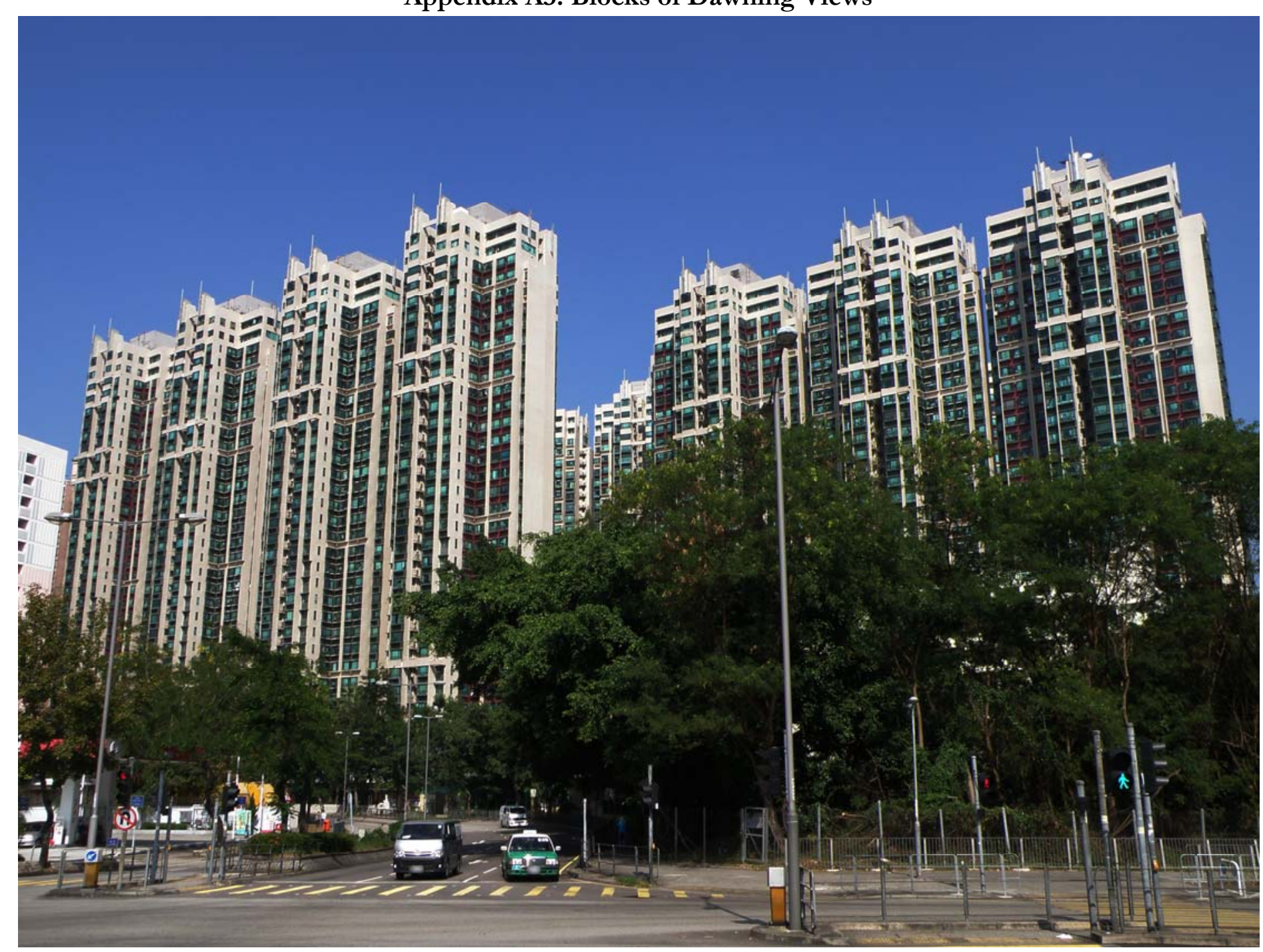


Appendix A4: Estate layout of Dawning Views

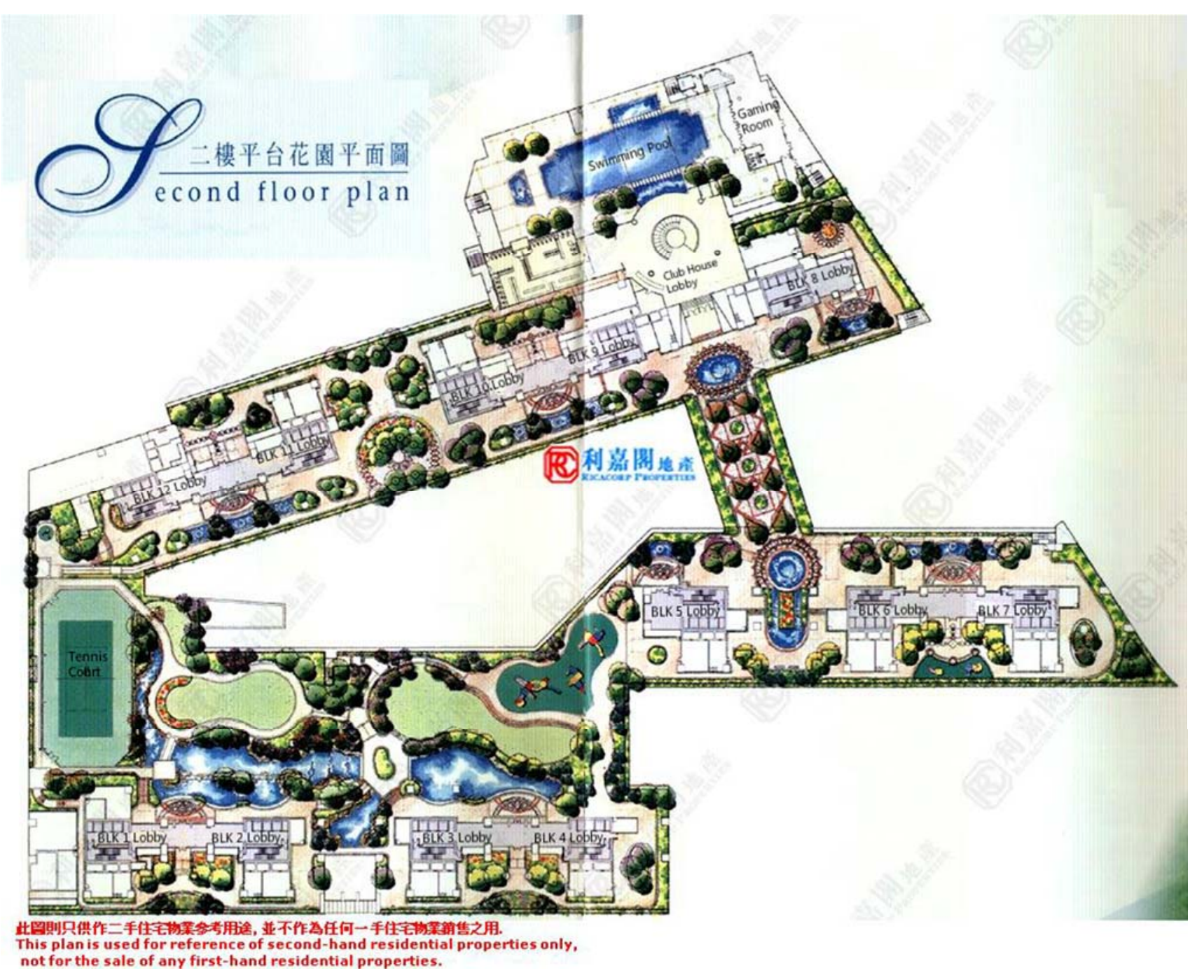


Appendix A5: Floor plan of Floor 8-17 in Block 12 in Dawning Views

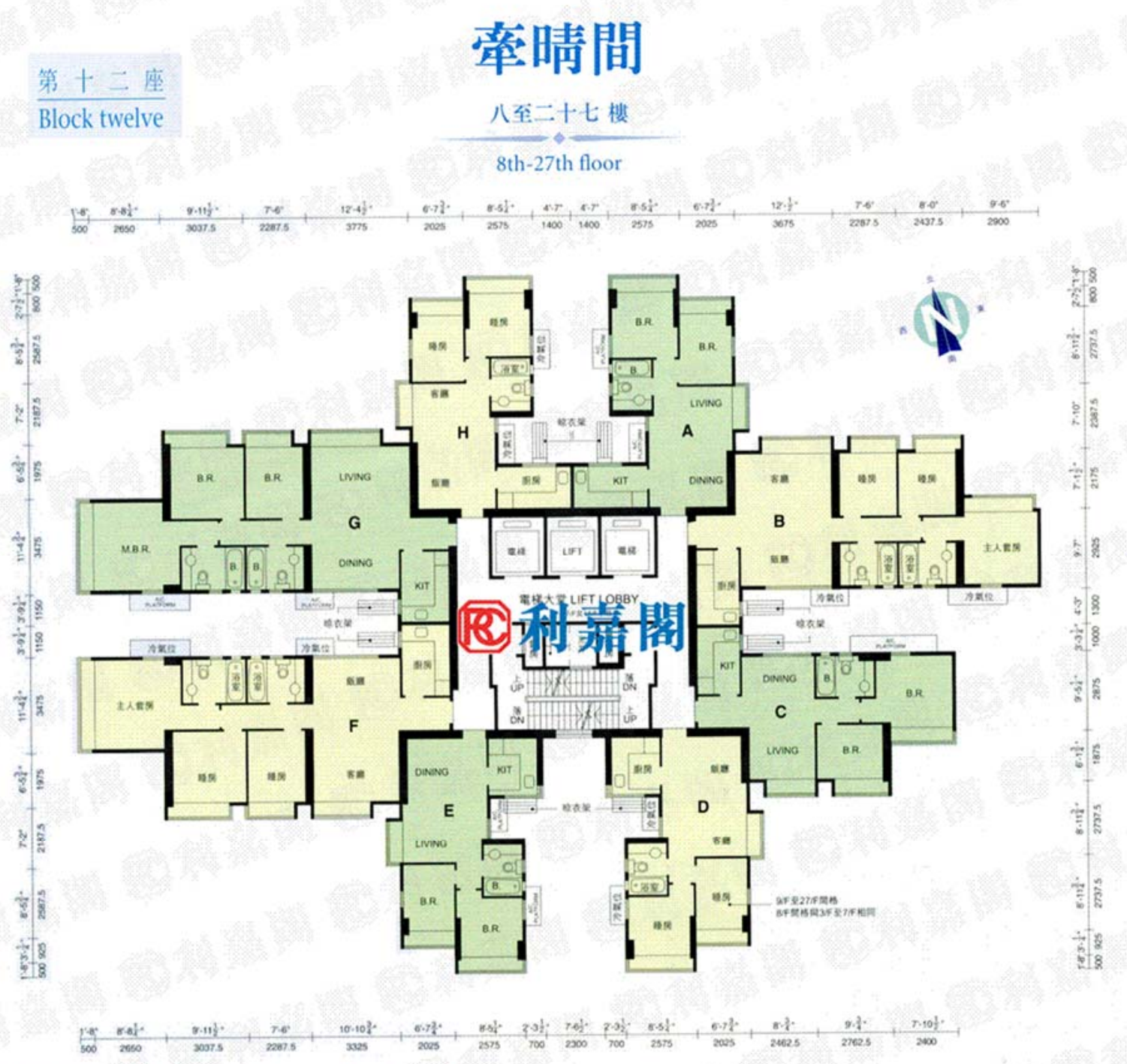

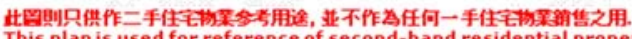

This plan is used forreference of second-hand residential properties only, 


0 Home Blog-Squarefoo $\times+$
$\leftarrow \rightarrow \circlearrowright \mid$ squarefoot.com.hk/home-blog $\quad \times$

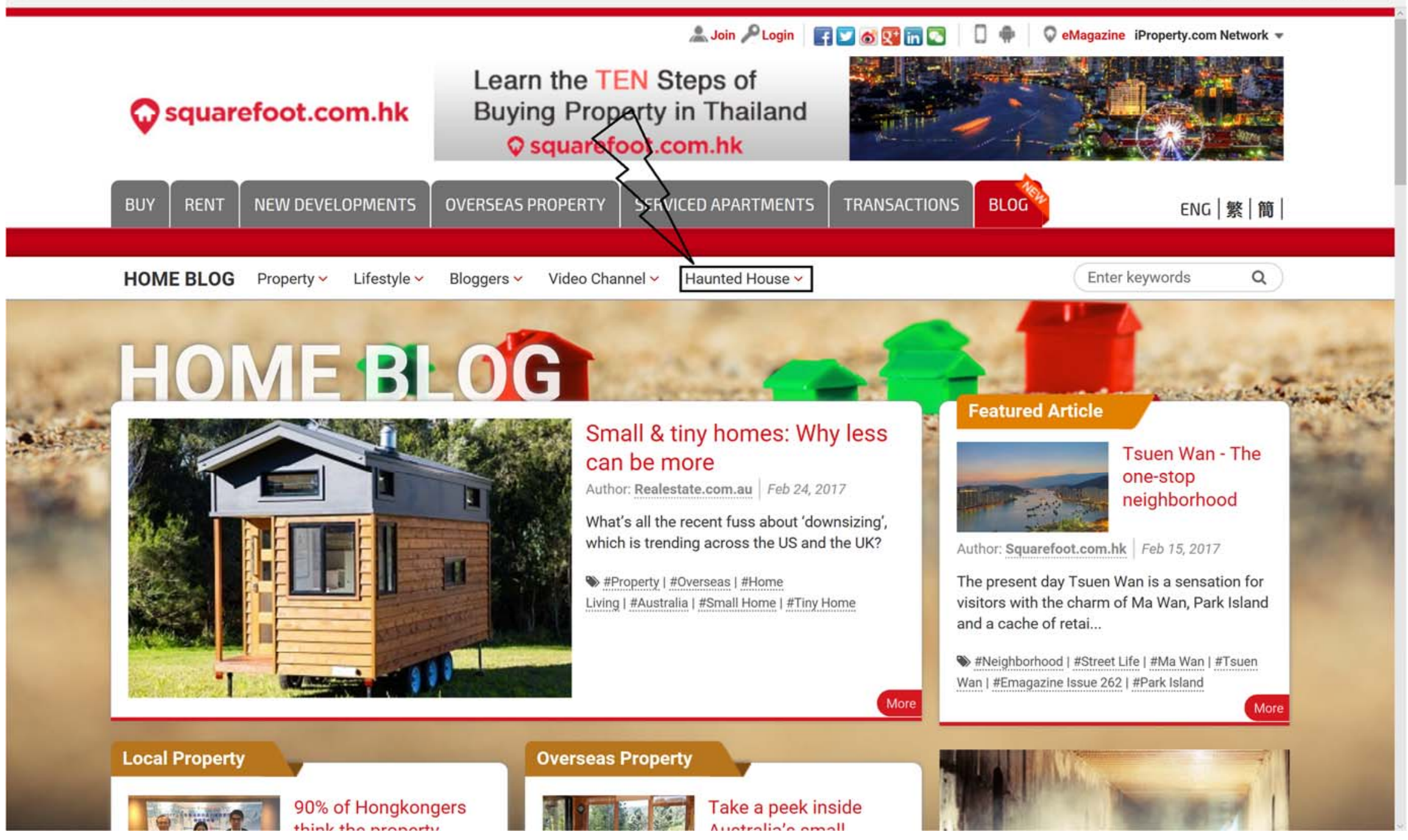




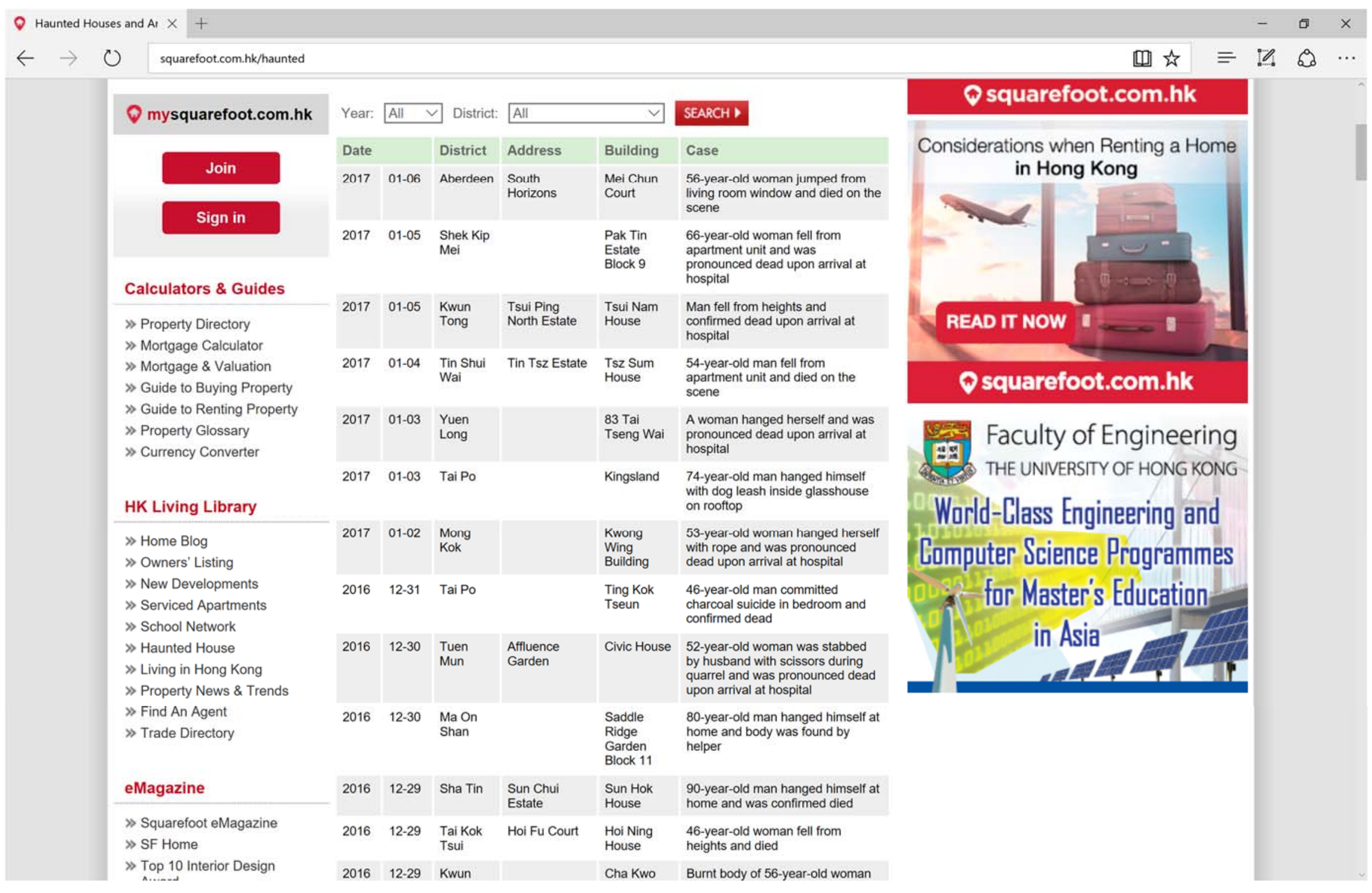


Appendix B2: Screenshots of Spacious.com.hk
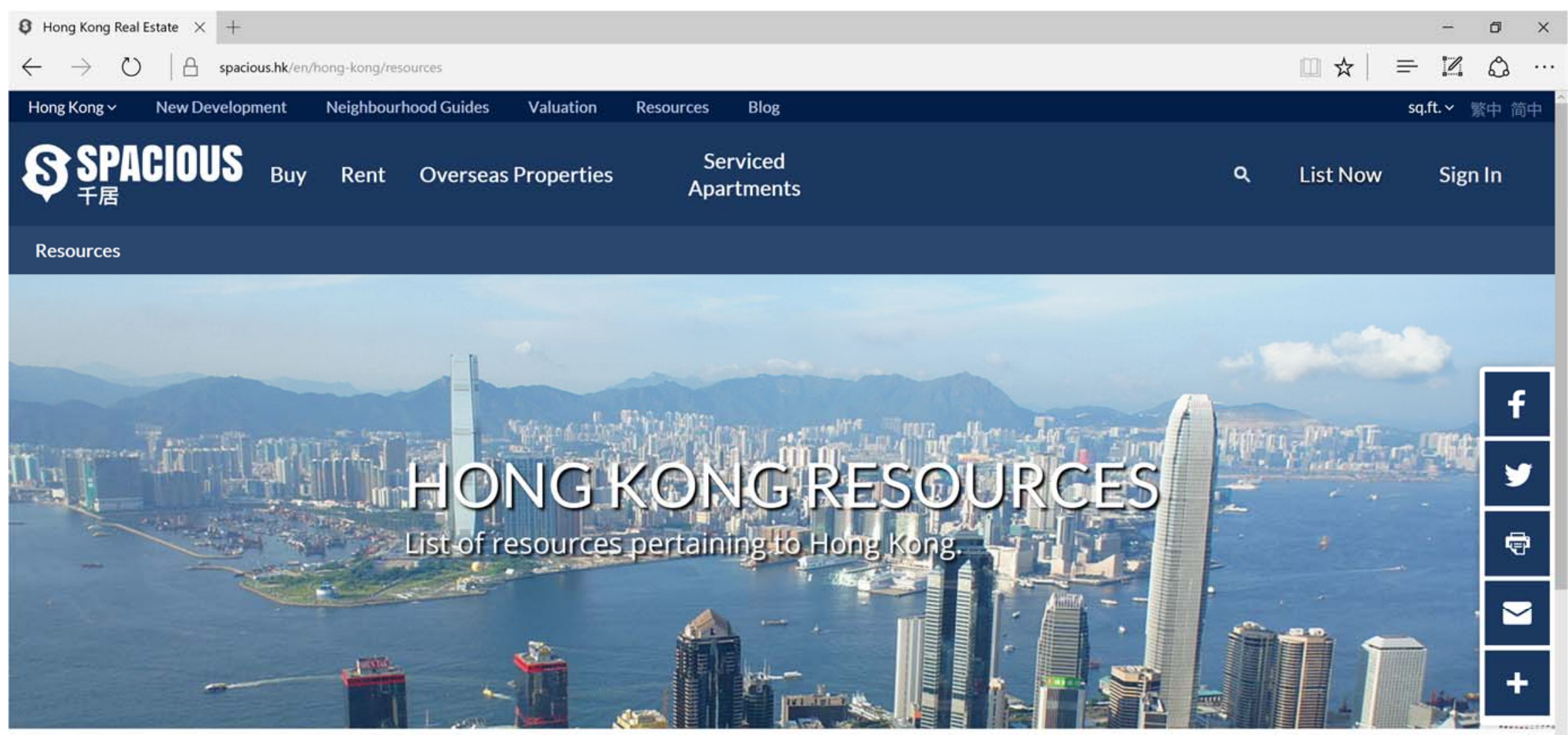

\section{(9) \\ Find all haunted houses in Hong Kong}

Schools

Find all schools in Hong Kong 


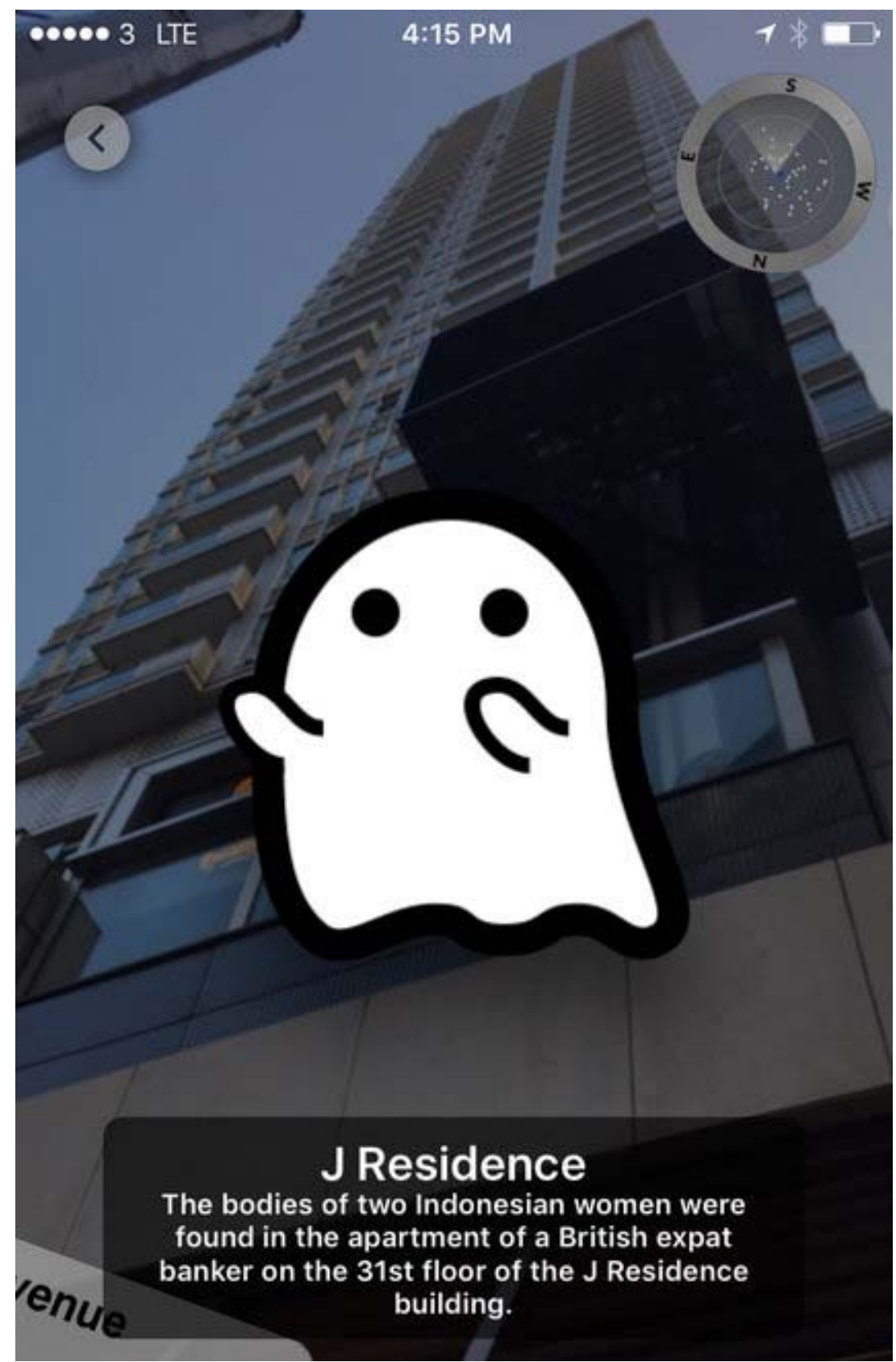




\section{SSPICHOUS}

\section{Select Neighbourhoods}

\section{Price}

Area $\checkmark$ AnyBeds

$\longdiv { \operatorname { M o r e } v }$

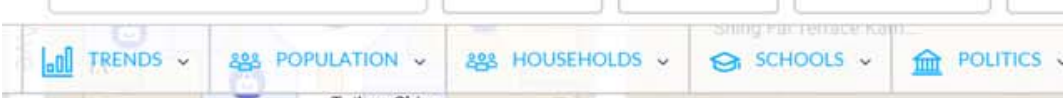

(5) $5^{\text {Gigasports }} \begin{array}{ll}\text { Taikoo Shing. } \\ \text { Horizon Gardens Yat.. }\end{array}$ 曰 (-) Shing Fai Terrace Yiu.

๑ Tai Koo Shing Rd

\section{SAVE SEARCH}

Q List Now

Sign In

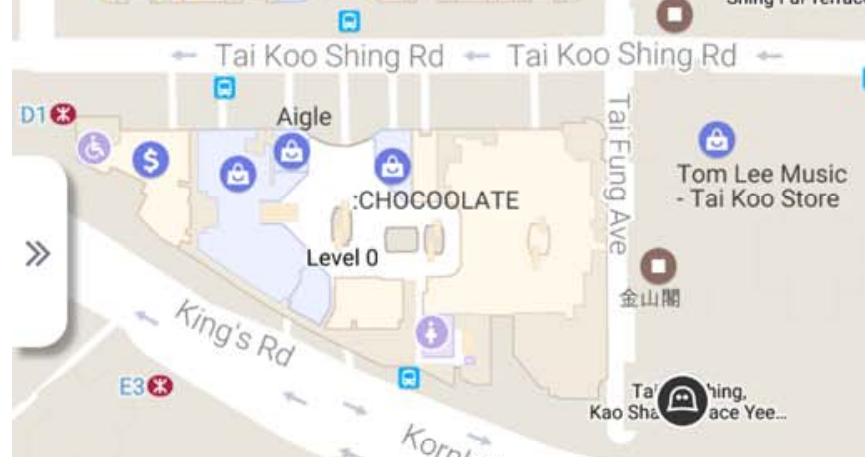

\section{@ HAUNTED}

\$ AFFORDABILITY HIDE OVERLAY 每星閣 ○

Kornhill Garden Block 8 Kornhill Garden apanese Casual Kornhill Garde

$$
\text { Kornhill Rd }
$$

C $\boldsymbol{*}$

Ricacorp Properties (8) Hang Lung Kornhill
Plaza Car Park Hong On St 1 The Floridian ower 1 Mount Parker Residences

Kornhill Block M

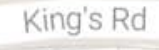
$\begin{array}{cc}\text { Taikoc } & \text { Taikoo Shing. } \\ \text { Shan Terraa } & \text { Kao Shan Terrace Tai. }\end{array}$

Taikoo Shing Tsui
Woo Terrace Po Yang
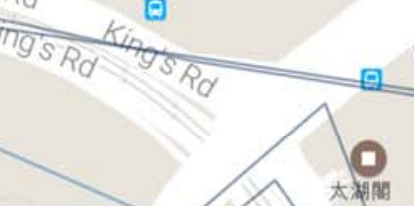

\section{(n)}
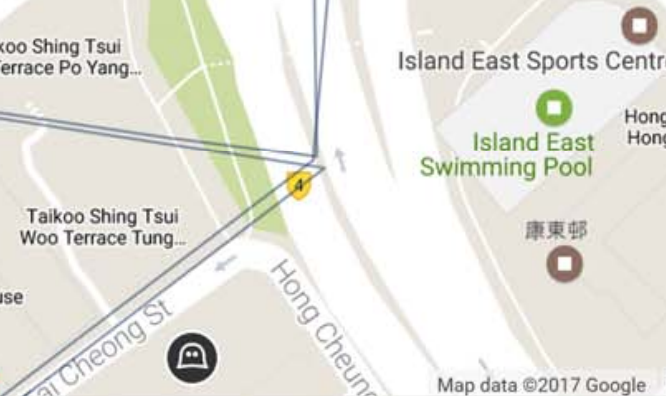

sland East Sports Centre

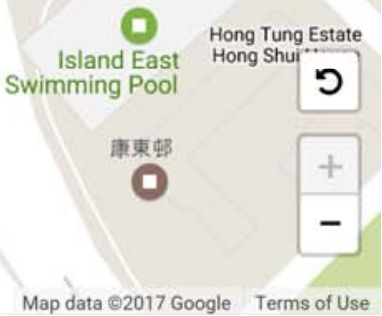

Map data $\odot 2017$ Google Terms of Use 